\title{
The Queensland Museum Expedition to Ngiangu (Booby Island): Rock Art, Archaeology and Inter-Regional Interaction in South-Western Torres Strait
}

\author{
Liam M. Brady ${ }^{1}$, Warren Delaney ${ }^{2}$ and Richard Robins ${ }^{3}$ \\ 1 Monash Indigenous Centre, PO Box 55, Monash University, Clayton VIC 3800, Australia Liam.Brady@monash.edu \\ 2 Queensland Museum, PO Box 3300, South Brisbane QLD 4101, Australia \\ 3 Everick Heritage Consultants Pty Ltd, PO Box 146, Red Hill QLD 4056 everick@bigpond.net.au
}

\begin{abstract}
In 1985 and 1990 a Queensland Museum research team visited the island of Ngiangu (Booby Island) to carry out investigations into the island's Indigenous and non-Indigenous archaeology. Forming the western boundary of Kaurareg traditional country, this small rocky island is an integral part of Kaurareg identity, and is well-known in maritime archaeology circles as a haven for European mariners shipwrecked while transiting the Strait. The research team, led by the late Ron Coleman, undertook rock art recording (including European historical writing), limited archaeological excavations, geological research and collected material culture objects from numerous shoreline caves. This paper reports on the archaeological outcomes of this project and reassesses earlier interpretations of the rock art record in the context of inter-regional interaction. The results indicate that cultural markers associated with the island reflect a local Kaurareg identity, as well as broader regional interaction with neighbouring Torres Strait Islander and Cape York Aboriginal groups.
\end{abstract}

\section{Introduction}

The shallow waters stretching between the northern tip of Cape York Peninsula and the southwestern Papua New Guinea coastline are home to 'Saltwater People' - Torres Strait Islander and Aboriginal peoples who are highly skilled marine specialists whose dependence on the sea extends beyond subsistence pursuits into the ritual and cosmological realm (e.g. David et al. 2005; McNiven 2003; McNiven and Feldman 2003; Sharp 2002). The islands are geographically divided into three main groups: Western (comprising the Top Western, Mid-Western and South-Western Island groups), Central and Eastern (Figure 1). Although the islands can be separated geographically, there is considerable ethnographic evidence to indicate that inter-regional interaction was a regular occurrence between island communities and the mainland to the north (Papua New Guinea) and south (Cape York) (e.g. oral traditions, kinship and exchange networks, and artistic traditions; see Brady 2005; Haddon 1904, 1908; Lawrence 1994; McNiven 1998; Moore 1979; Vanderwal 2004). While not all islands in Torres Strait were permanently inhabited, they all, to some extent, played various roles in the lives of Islander and Aboriginal peoples. These included neutral grounds (e.g. Moore 1972), seasonal hunting islands (e.g. Thompson in Moore 1979), and stopping-off points during long sea journeys across the Torres Strait seascape (e.g. David et al. 2009).

The aim of this paper is to compile and examine the results - many of them previously unpublished or unreported - of the Queensland Museum's expedition to Ngiangu. This project was carried out over two field seasons (1985 and 1990) by Queensland Museum staff under the direction of the late Ron Coleman. The central objectives of the fieldwork seasons was to investigate the Indigenous and European histories associated with the island by systematically documenting the rich collection of rock paintings (Indigenous and European historical writing), and carrying out detailed geological and archaeological surveys of the island's numerous shoreline caves. After being granted permission to use the Expedition's rock art photographs for his $\mathrm{PhD}$ on Torres Strait rock art, LMB was invited to assist the team in writing-up the results of the two field seasons. In this paper, attention is focused on discussing the Indigenous history of Ngiangu and recent archaeological trends, particularly those of inter-regional interaction from the region (a systematic analysis of the European historical writing is being undertaken by Jane Fyfe). The paper also reassesses previous assumptions about links between Ngiangu and surrounding regions (e.g. Southeast Asia).

\section{Ngiangu}

Situated in the South-Western group of Torres Strait islands (also known as the Kaurareg Archipelago), Ngiangu lies at the western approach to Torres Strait $\left(10^{\circ} 36^{\prime} \mathrm{S}, 141^{\circ} 55^{\prime} \mathrm{E}\right)$. The island is a steep-sided 6ha flattopped island encircled by a fringing coral reef and riddled with numerous shoreline caves (Adze Cave, Mystery Man Cave, Anzac Cave, Cathedral Cave, Tip Cave, Fern Cave, Post Office Cave, Pouri Pouri Cave, Pot Hole Cave) (Figures 2-3). Ngiangu represents the western limit of the traditional territory of the Kaurareg Aboriginal people. The Kaurareg were, until the arrival of Europeans, largely based at Muralag (the largest island in Torres Strait), yet travelled to, and exploited the resources from their neighbouring islands, such as Kirriri, Ngurupai, Palilag Giralag and Ngiangu (e.g. Haddon 1912:1-2; Moore 1979; R. Wasaga, pers. comm., 2003). The Kaurareg Archipelago is a key group of islands in the region positioned at the frontier between Melanesianinfluenced Islanders and Aboriginal hunter-gatherers at Cape York (Brady and Kaurareg Aboriginal Community 2007; Moore 1972). The sustained interaction between Kaurareg and Cape York Aboriginal groups and Torres Strait Islanders thus makes the Kaurareg Archipelago a distinctive transition zone for cultural influences and a key location for archaeological research addressing issues of inter-regional interaction (Brady and Kaurareg Aboriginal Community 2007; Moore 1972). 




Figure 1. Torres Strait, northeastern Queensland (circled: South-Western group of Torres Strait islands, including Ngiangu). 




Figure 2. Plan of Ngiangu (map redrawn from original held at the Queensland Museum).



Figure 3. Profile of Ngiangu (lighthouse not to scale) (map redrawn from original held at the Queensland Museum). 
Ngiangu was named 'Booby Island' by European ship captains in the late eighteenth century on two separate occasions - James Cook in 1770 (Beaglehole 1955) and William Bligh in 1789 (Bach 1986) - owing to the sizeable population of Boobies (Sula leucogaster) which could be seen nesting and flying around the island. Presently uninhabited, Ngiangu did have a small European population consisting of lighthouse keepers and their families beginning in 1890 and lasting until 1992 when the lighthouse became fully automated and destaffed (Nicholson 1996:284).

\section{Geology}

Together with the Western chain of Torres Strait islands scattered northwards from Muralag through Mua, Badu and Mabuyag to Dauan, Ngiangu is a visible remnant of the Cape York/Oriomo tectonic ridge. Ngiangu's geology consists primarily of outcroppings of the Carboniferous Torres Strait Volcanics Group (see von Gnielinski et al. 1998 for further details). These rocks are acid volcanics with the predominant type observed being a porphyritic crystal tuff. This rock exhibits angular quartz crystals measuring up to $0.5 \mathrm{~cm}$ across, set in a fine-grained siliceous groundmass.

Three principal structural trends are present on the island along which faulting and fracturing have occurred and are oriented as follows:

- $\quad$ Trend I NE/SW

- $\quad$ Trend II ESE/WNW

- $\quad$ Trend III NW/SE

The structures are generally steep-dipping and, in the case of Trend I features, may form zones of shearing several metres wide. Siliceous infilling of the shears is prevalent whilst pyritic alteration zones are spatially associated with Trend III structures.

A direct correlation is obvious between the shape and the location of the caves surrounding the island and the three principal structural trends. Main cave openings have developed along fractures as physical weathering (wind and wave action) coupled with seasonal percolation of water from monsoonal rains have enlarged pre-existing zones of weakness. This has caused roof collapse along fracture planes and facilitated the development of cavities.

The regular influx of wet season groundwater has resulted in the leaching of silica from the volcanic country rock. This is precipitated as chalcedonic encrustations on cave walls and ceilings as the solutions migrated down cave-controlling geological structures. This secondary silica skin coating has been responsible for masking and damaging the rock art in some locations.

The 1985 Queensland Museum survey was conducted in the middle of the dry season (July) when water movement is usually at a minimum. In spite of this, ground water could be seen dripping into two caves (Tip Cave and Fern Cave) at several points. The continual movement of solutions into Fern Cave has resulted in the presence of more secondary silica in this cave than any other.

Evidence of previous higher sea-levels is manifest by the occurrence of an $8-12 \mathrm{~cm}$ thick consolidated coralline sand deposit on the floor of Pouri Pouri Cave and the well-stratified and sorted sand deposit present in Fern
Cave. In Fern Cave this comprises $20 \mathrm{~cm}$ of packed coralline sand containing some roof fall detritus overlaying $25 \mathrm{~cm}$ of large coral fragments. At both locations these deposits immediately overlie volcanic bedrock. With the exception of the higher elevated caves (Adze Cave, Mystery Man Cave and Tip Cave), indications of similar coral rubble and sand deposition on the cave floors was observed.

\section{Ngiangu's European Presence}

The earliest European reference to Ngiangu comes from the Dutch in the mid-1750s who named the island 'Rijder Island' (Heeres 1899). However, the first record of a European landing on the island did not come until Cook visited in 1770 (Beaglehole 1955).

Following this early phase of discovery Ngiangu became an importance place for mariners during the late eighteenth and early nineteenth centuries when development of the Australian colonies and maritime activities intensified (see Nicholson 1996 for an in-depth review of Ngiangu's maritime history). The island acted as a stopping or staging point for those ships navigating the treacherous waters of the Great Barrier Reef and Torres Strait. Most importantly the island acted as a safe haven for shipwrecked mariners and as a European 'Post Office'. From the early 1800 s Post Office Cave was used as a stores cache for shipwrecked mariners and a place where mail could be left for passing ships (e.g. Ashmore 1844; King 1827; MacGillivray 1852 I:122-123; Nicholson 1996; Rhodes 1934; Singe 1979:46; Stewart 1845; Stokes 1846:371).

Ngiangu continued to be maintained as a refuge well into the 1870s until government administration shifted from Somerset at Cape York to Thursday Island (Prideaux 1988:73; Sharp 1992). As this port grew, the importance of Ngiangu to mariners as a refuge dwindled. However this situation was short-lived. In 1890 the construction of a lighthouse on the island was completed and a permanent European presence to staff this navigation aid commenced - a presence which continued until 1992 when the light was automated (Nicholson 1996:284-288).

In addition to Europeans documenting their visits to the island in logbooks and official correspondence they also inscribed the rock walls in Post Office Cave with writing and symbols (Figure 4). A sequence of historical events from the earliest visiting mariners (the Harbinger 8 May 1849) to the 1990 anniversary of 100 years of light, can still be interpreted from the cave wall historical writing (see Delaney 1990 for further details).

\section{Ngiangu's Indigenous History}

Ethnographic information pertaining to Ngiangu is scarce in comparison to the rest of the Strait. The island features in an oral tradition collected in 1967 by amateur anthropologist Margaret Lawrie from a well-known Kaurareg Elder, Wees Nawia. The story, 'Pötikain and Ngiangu', describes the origin of the island with the mythical giant Ngiangu being ordered by Pötikain to walk away from Muralag's west coast until Pötikain could no longer see him. At this point both Pötikain and Ngiangu turned to stone (see Lawrie 1970:5 for further details).

During Coleman's initial visit to the island in 1985 he also collected a second-hand account of a current 'legend' about the island from the then lighthouse keeper, Mr. G. 
Page. Coleman (nd-a:10) reports that a dogai, a mythical devil-woman whose character features in many oral traditions throughout Torres Strait, haunted one of the caves (Pouri Pouri Cave) thus preventing many 'Islanders' from staying overnight on the island. Coleman (nd-a:10) reports that he did not have time to verify this story.

No reference has been made in the literature to observing Kaurareg, or any other Torres Strait group for that matter, on Ngiangu although some inferences have been made regarding Indigenous use of the island. Samuel Ashmore (1844:2) reported that, 'I have every reason to believe that the natives from the neighbouring islands occasionally visit it during the N.W. monsoon, for the purpose of procuring the turtles eggs, as also those of the innumerable birds from which the island takes its name'.

There are other indications of pre-European contact use of the island. Coleman (nd-a:7) notes that '[o]ld dugong bones were found in the shallows on the western side of the island'. Dugongs were (and continue to be) a main subsistence resource for Torres Strait Islander and Aboriginal groups and they also played a major role in religious and ritual practices (e.g. David et al. 2009; McNiven and Bedingfield 2008; McNiven and Feldman 2003). Observations by King (1827:385-386) and Ashmore (1844) concerning sizeable numbers of turtles and turtle eggs and bird eggs would have made the island an attractive destination. Additionally, stone adze blades recovered from one of the caves, the extensive collection of rock paintings, and the stone arrangements found on the island point towards a clearly visible Indigenous presence on the island (see below).

\section{Stone Arrangements}

Recent in-depth research into the nature of stone arrangements (e.g. cairns, fish traps, standing stones, animal effigies, circles) in the Torres Strait region has provided important insights into their creation, function, symbolism and links with colonial processes. For example, David et al.'s (2004a) excavation of a stone feature from the large Argan stone arrangement complex located on an isolated ridge-top on Badu revealed a basal date of $604 \pm 36$ BP (Wk-11949), indicating its likely construction sometime between AD 1300 and AD 1400. This provides the first indication of the time-depth associated with a distinctive ritual practice site (David et al. 2004a). At Evans Point at Cape York, McIntyreTamwoy and Harrison (2004:37) recorded numerous stone cairns which they interpreted as being part of 'a large turtle increase site associated with dozens of stone agu [cairns]'.

The first recorded observation of stone arrangements on Ngiangu was by King (1827:385-386) during a brief visit to the island in 1820: '[s] everal piles of stones were observed, that had been heaped up by the crews of the various ships passing by, as relics of their visit'. Stokes (1846:371-374) also mentions that during his visit to the island in 1839 'a few of the stones mentioned by Captain King are still to be seen on the summit'. The first reference to the piled stones being constructed by Indigenous people comes from Ashmore (1844:2) who noted that 'the pyramids of stones erected by the natives in the summit of the islands, [are] evidently ... a sort of rude nests [sic] for the reception of these [bird] eggs'.
Coleman (nd-a:64) noted '[t]hese were very likely Islander 'turtle lookouts' similar to those extensively described by Brierly [at Evans Bay, Cape York]'. Similar stone cairns have been noted by Moore (1979) on Muralag and interpreted as turtle lookouts.

During the Queensland Museum survey Coleman (nda:64) identified two sets of stone arrangements: (1) the remains of a low stone wall which 'originally surrounded the water wells'; and (2) three stone circles (Figures 5-7). However, the stone cairns observed in the early-to-mid1800 s were not located suggesting they had been dismantled over time, possibly by the generations of lighthouse keepers and their families, or visitors to the island. Coleman (nd-a:64) describes the stone circles recorded during fieldwork as:

On the top of the island, at the otherwise featureless and barren southeast corner, are two and the remnants of a third roughly circular stone enclosures. The larger of the two intact structures measures approximately 2.5 metres on the longer axis and has an average wall height of .7 of a metre ... They are approximately 100 metres from the easternmost light station cottage, and are set back from the verge of the island cliff so that a view of the reef below is impossible.

The other set of circular stone arrangements are found at the northeastern corner of the island and are 'adjacent to, and probably originally surrounding, two naturallyformed fresh water seepage catchments' (Coleman 1991:4-5). Coleman (1991:5) notes they were probably not used as turtle lookouts given their poor view of the reef, and instead speculates they 'may have been sites for increase rituals'.

Material from a sieved uncontrolled sample was taken from the interior of the larger of the two stone structures from the surface to a depth of $10 \mathrm{~cm}$ in 1990. Materials recovered include fragments of charcoal, pumice, tumbled (water worn) clear glass, white glazed ceramic, animal bone (bird and possibly turtle), coral, assorted marine shells, water-worn pebbles and tin. Three whole shells (two bivalves, one conic gastropod) were also recovered.

While it has been noted that stones have been used by lighthouse keepers for various tasks such as creating pathways and edging gardens (Coleman 1991:4), the relatively intact nature of the stone circles and their location away from the lighthouse keepers' cottages, suggests they may have served a purpose in the past. The stone cairns identified by Ashmore, but not recorded by the Queensland Museum team, sound similar to cairns recorded from Muralag and Cape York which are linked to turtle lookouts and turtle increase ceremonies. McIntyre-Tamwoy and Harrison (2004:38) noted that stone circles at Cape York were commonly found in association with stone cairns which, based on a careful reading of the Brierly journals from the mid-1840s, lead them to suggest that sites where stone cairns and circles were located 'may have had a dual initiation/bora and increase function'. Given the historical observations of stone cairns on the island, coupled with the existing stone circles, we are presented with a similar situation to that at Cape York. We acknowledge that it is difficult to ascertain the exact nature of the Ngiangu stone arrangements without knowing what disturbances to the stone structures have taken place over a century of 
Figure 4. Historical writing at Post Office Cave.
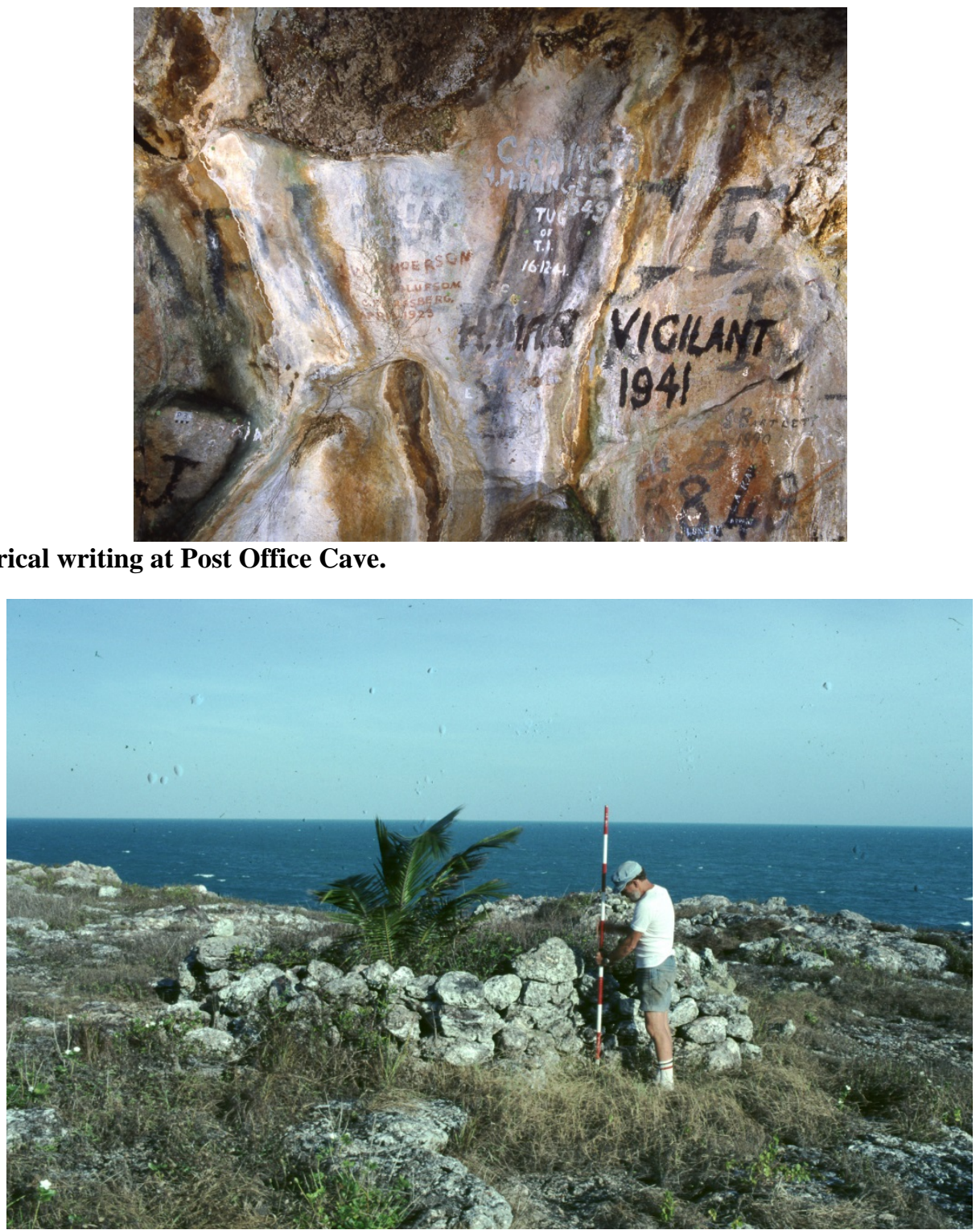

Figure 5. Stone arrangements at Ngiangu.

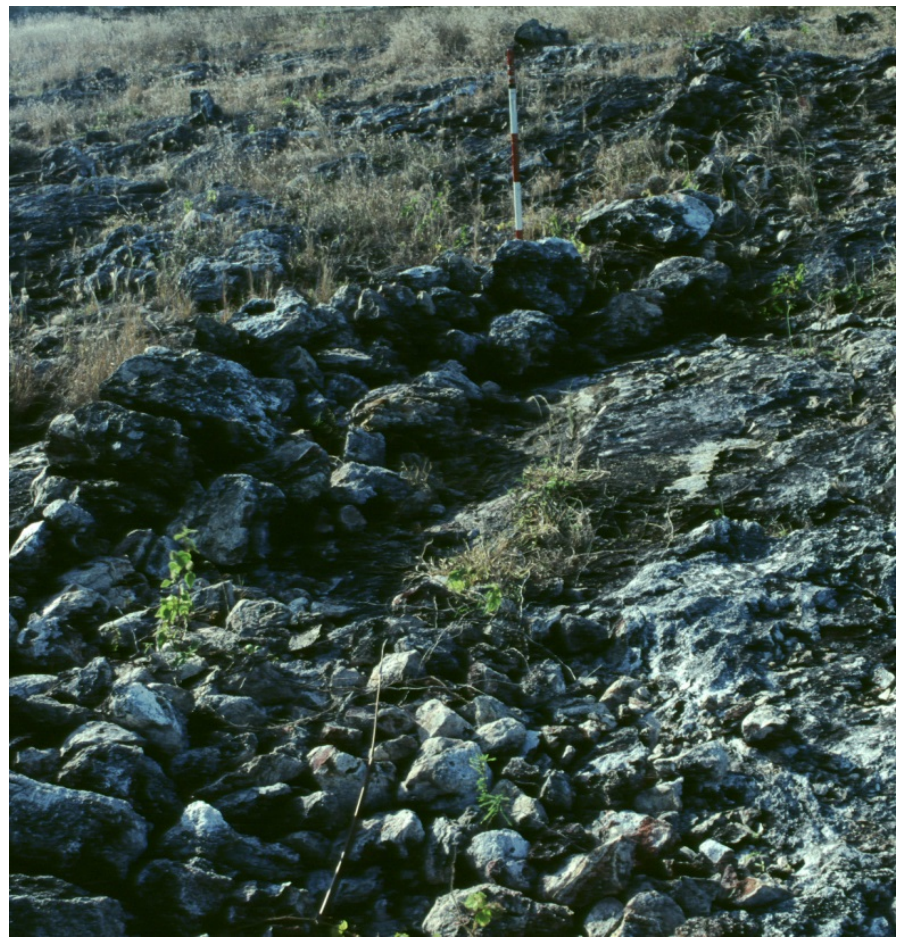

Figure 6. Stone arrangements at Ngiangu. 

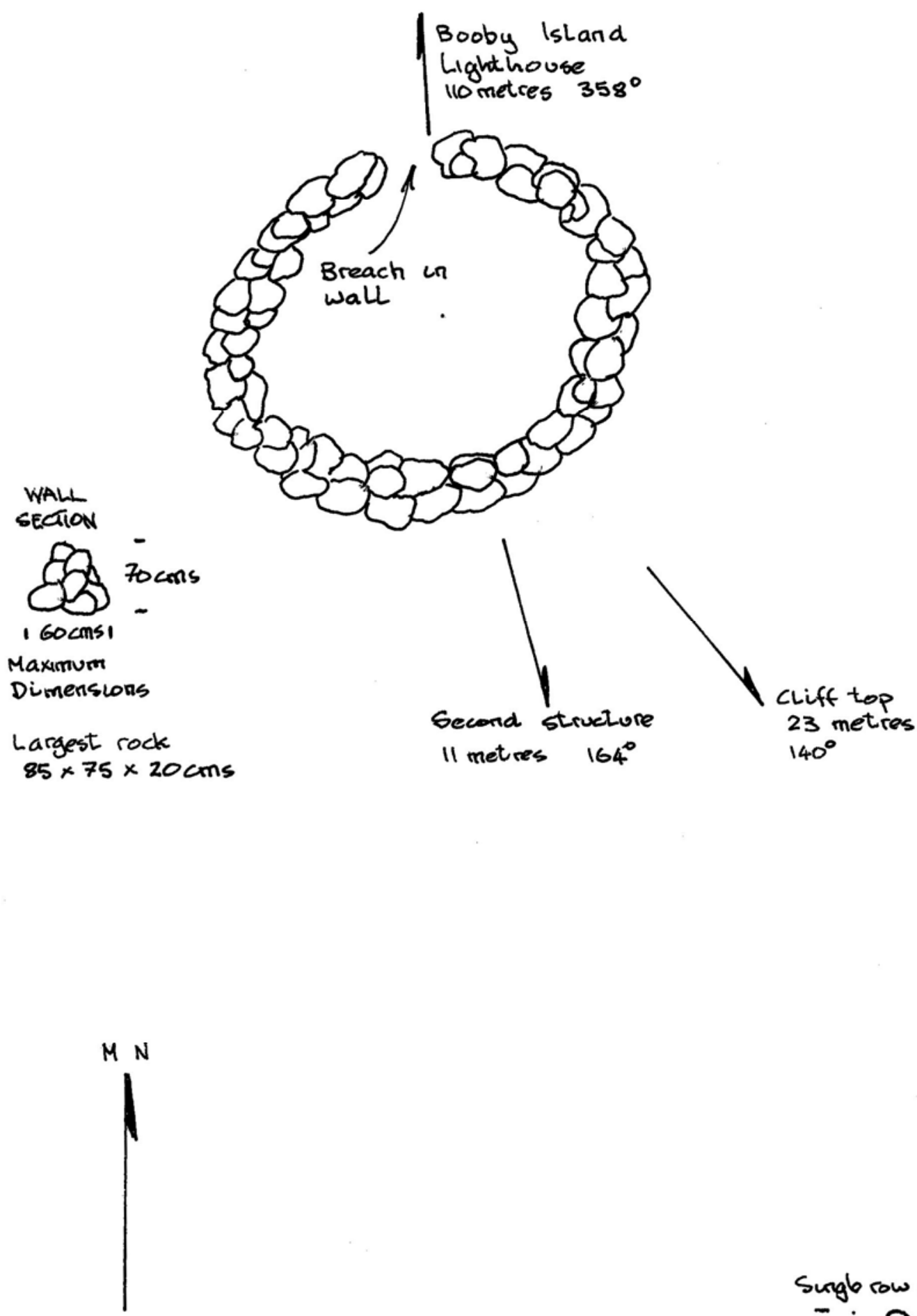

BOOBY ISLAND

STONE STRUCTURES

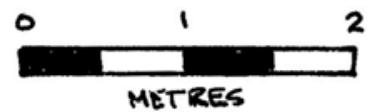

Sungle row of stones

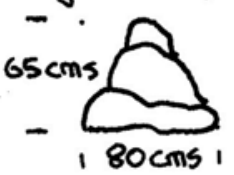

Maximum Dimensions

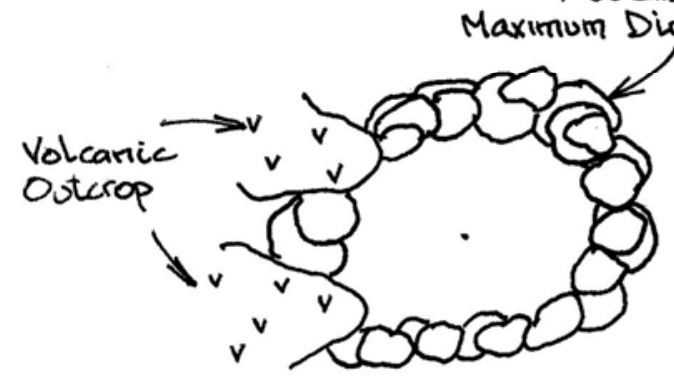

Figure 7. Map of 'stone structures' recorded by the Queensland Museum in 1985. 
European occupation of the island. However, the presence of the Ngiangu stone structures combined with historical and ethnographic evidence suggests they may have had a role in Kaurareg magico-religious beliefs (see also Greer et al. 2011).

\section{Pottery}

During the 1990 fieldwork season, thick coarse earthenware pottery fragments were recovered from the surface of Pot Hole Cave. Prior to this discovery no pottery had been recorded anywhere in the Strait. Indeed, it was Haddon (1890:303) who noted after his first visit to the region in 1888 that ' $[\mathrm{t}]$ here never has been any pottery' in Torres Strait. While details of the Ngiangu pottery remained unpublished until now, recent archaeological research from the Western and Eastern islands has recovered a significant number of pottery sherds which has been crucial to further developing our understanding of Torres Strait cultural history.

Only three other sites in Torres Strait feature pottery: Mask Cave at Pulu in the Mid-Western islands (surface and subsurface finely-made red-slipped wares dating as early as 2400-2600 cal BP; McNiven et al. 2006; see also David and McNiven 2004); Mui at Mabuyag in the MidWestern islands (thin-walled, plain ware conjoining sherds dating back to around 1500 cal BP; Wright and Dickinson 2009); and from Sokoli and Ormi at Dauar in the Eastern islands (red slip and brown slip sherds with deposition dates of around 1970 cal BP and 700 cal BP; Carter 2004).

Partial reconstruction of the Ngiangu potsherds revealed two separate vessels (Coleman nd-a:65) (Figures 8-10). Investigations into the shape and source of one of the sherds have shown that it is from a 'small carinated bowl with a deep rim' and the vessel was not as crude as it originally seemed due to spalling in the firing process (Cox and Watchman 2000:1). However no definitive conclusion could be reached regarding the source of the clay although chemical analysis did reveal some consistencies with southern Papuan pottery such as an unusually high chlorine content (probably due to 'use of seawater during preparation' or 'post depositional leaching in a marine environment'), and the lack of shell used as a temper indicating that the pot was not tempered with beach sand (Cox and Watchman 2000:1-3). Other analyses of the pot sherds give a provenance of possibly Yule Island on Papua New Guinea's south coast (G. Summerhayes, pers. comm. to RR, 2000) and possibly a Papuan Gulf or Port Moresby origin or even Southeast Asia (P. Bellwood, pers. comm. to RR, 1990).

Consequently, there remains considerable uncertainty regarding both the origin of the clay potsherds and their antiquity. Preliminary observations offered by Summerhayes and Bellwood point towards a possible southern Papua New Guinea influence, although this assumption requires further archaeological testing.

Some additional observations can still be made using comparisons with the pottery recovered from Pulu, Mabuyag and Dauar. The Ngiangu sherds are much thicker and coarser in appearance and lack any type of slip and was recovered from the surface, while only two sherds from Pulu were found on the surface - all remaining sherds from Pulu, Mabuyag and Dauar were recovered through excavation. Detailed mineralogical analyses for Pulu and Mabuyag pottery suggest local manufacture, while the Dauar sherds are suggested by Carter (2004:307) to have been manufactured on the New Guinea mainland. The lack of detailed mineralogical analysis of the Ngiangu pottery makes it difficult to establish any firm evidence at this time of local manufacture or exchange relationships involving pottery between Ngiangu and other Torres Strait islands or southern Papua New Guinea. Consequently, until further research is undertaken, the enigmatic Ngiangu pottery must be viewed as being substantially different to that recovered elsewhere in the Strait.

\section{Excavations - Adze Cave (1990)}

Adze Cave - named by a former lighthouse keeper who discovered two stone adzes inside - is a small cave in the northern face of the steep slope of a small inlet on the southeastern side of the island (Figure 11). The aim of the excavation was to determine if the cave retained any cultural deposit that may assist in identifying the group(s) that used the island, what they used the island for, and when. In particular it was hoped that excavation would provide information on the origin of the adzes. Mystery Man Cave lies on the southern face opposite. The area adjacent to the cave has been used as a dump, and as a result there is a considerable accumulation of rusted iron, plastic chair covers, batteries, broken china and broken glass at the mouth of the cave. A coconut tree at the mouth of the cave has helped to retain the cave deposit. Immediately inside the entrance the cave trends northeast/southwest. The southwestern chamber is approximately $3 \mathrm{~m}$ long while the northwestern chamber is approximately $12 \mathrm{~m}$ long. The maximum width of the chambers is $2 \mathrm{~m}$ and the height is less than $2 \mathrm{~m}$. Roof fall occurred in several places in the cave. Three 'pot holes' had been dug into the deposit some time previously. No cultural material was evident in the pot holes or in their spoil heaps.

Two quartz pebbles, an adze blade (see below), and a single flake were found on the surface of the deposit at the time of excavation and collected. Charcoal fragments were also found on the cave floor.

The surface of the cave deposit was a moist black deposit (Munsell Soil Colour: 10YR 2/1) with a pH of 66.5 . Fern roots were evident on the surface and a mat of root material from a palm tree was found in the lower (eastern half) of the square. Roof spall was evident thoughout the deposit. Given the roof fall and the excavated pot holes in the deposit within the cave, a $50 \mathrm{~cm}$ $x 50 \mathrm{~cm}$ test pit was excavated at the sloping entrance to both chambers (Figure 11). This was also the part of the cave that had the greatest living area and the most natural light. The pit was excavated with a trowel and brush in volumetrically standard units (bucket spits) of about $2 \mathrm{~cm}$ in thickness to a mean depth of $40 \mathrm{~cm}$ when bedrock was encountered. All the excavated deposit was sieved through $3 \mathrm{~mm}$ and $6 \mathrm{~mm}$ sieves.

From the moist, black surface the deposit graduated to very dark brown (10YR 2/2) to very dark greyish-brown (10YR 3/2) at the base. The deposit was in parts organicrich and increased in moisture with depth. It was very pedal, as a result of the precipitation of silica from the parent rock and its reformation in the deposit. A mat of rootlets occurred at the surface of the deposit and 


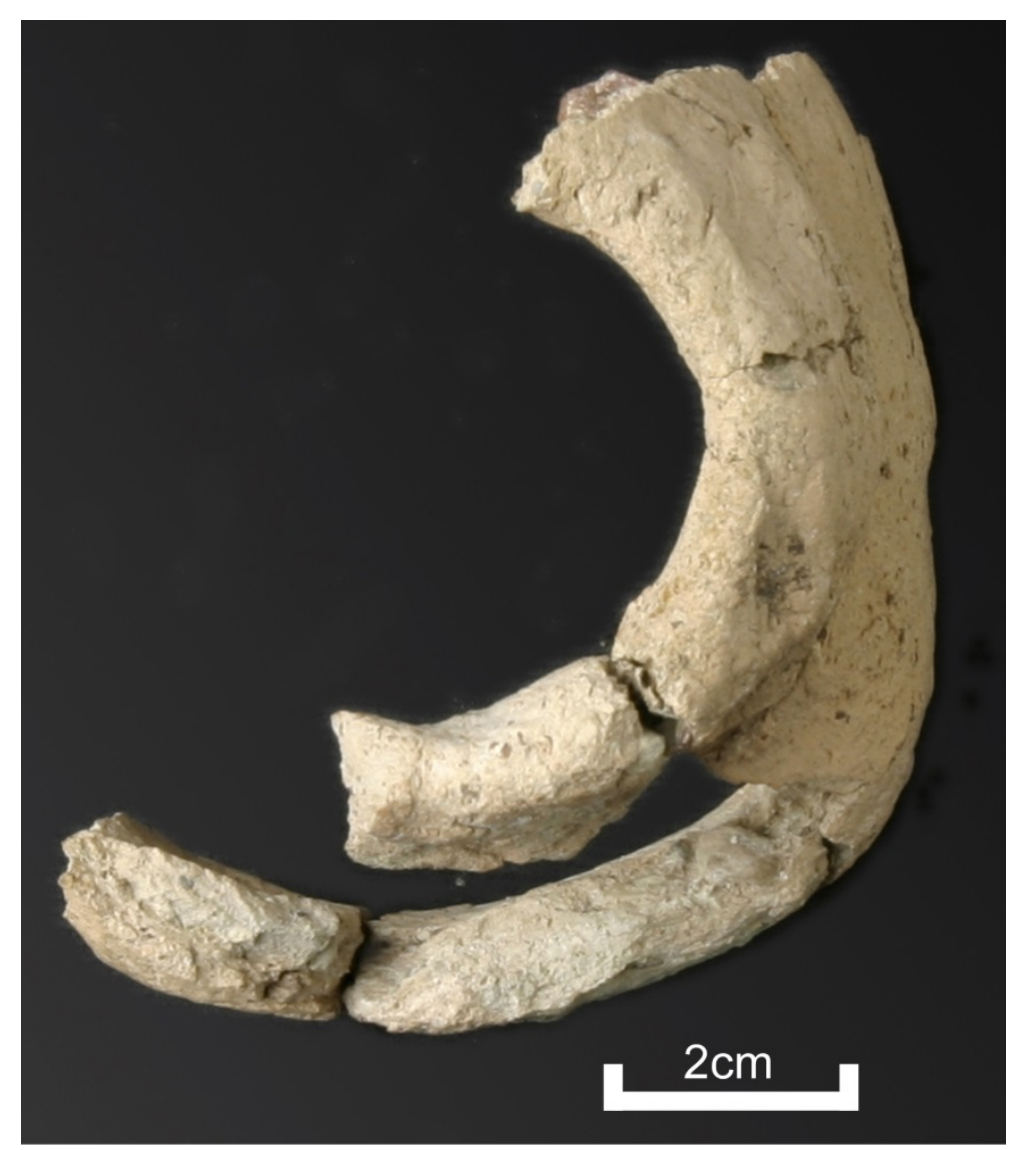

Figure 8. Pottery fragment (vessel \#1).

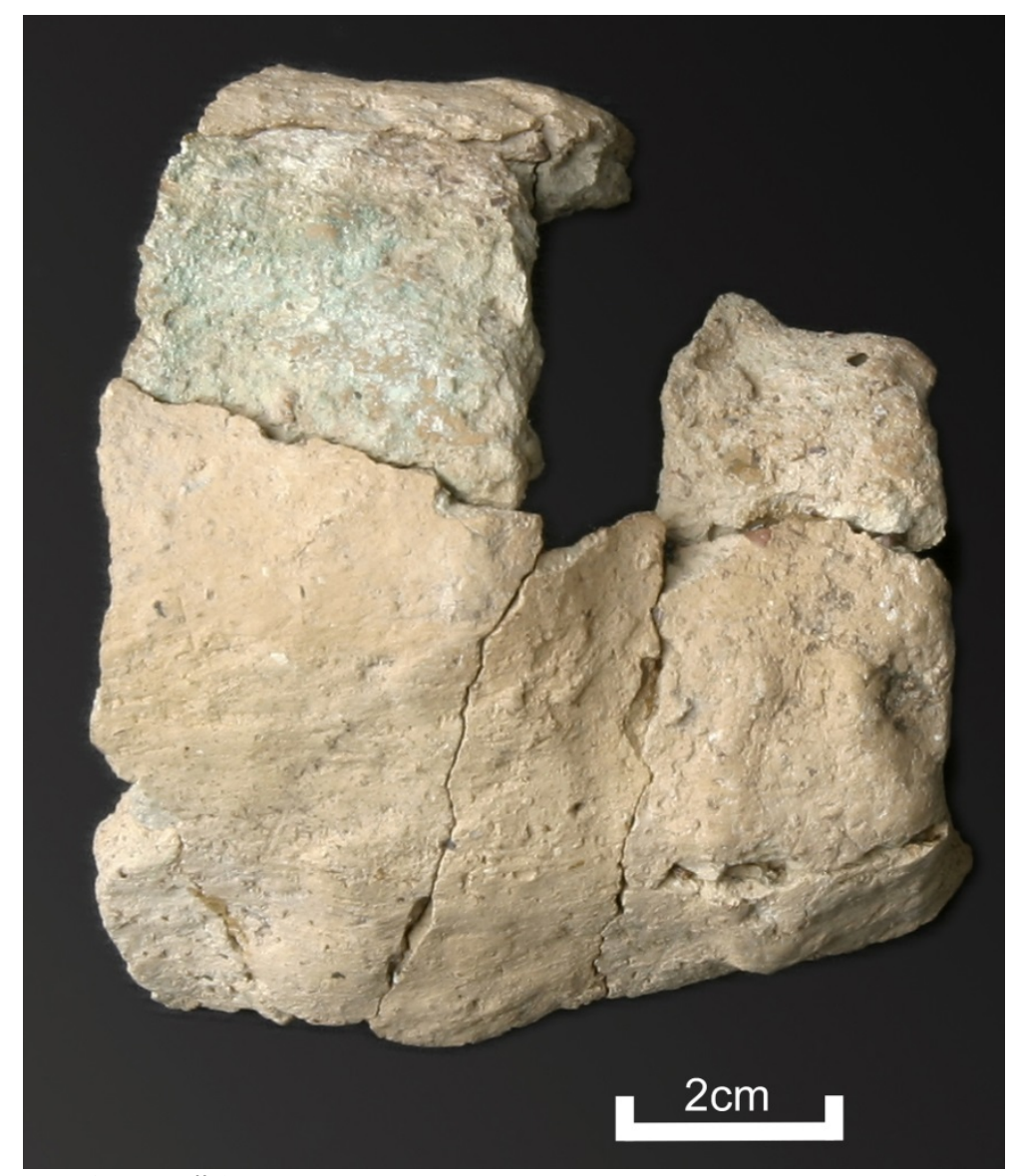

Figure 9. Pottery fragment (vessel \#1). 


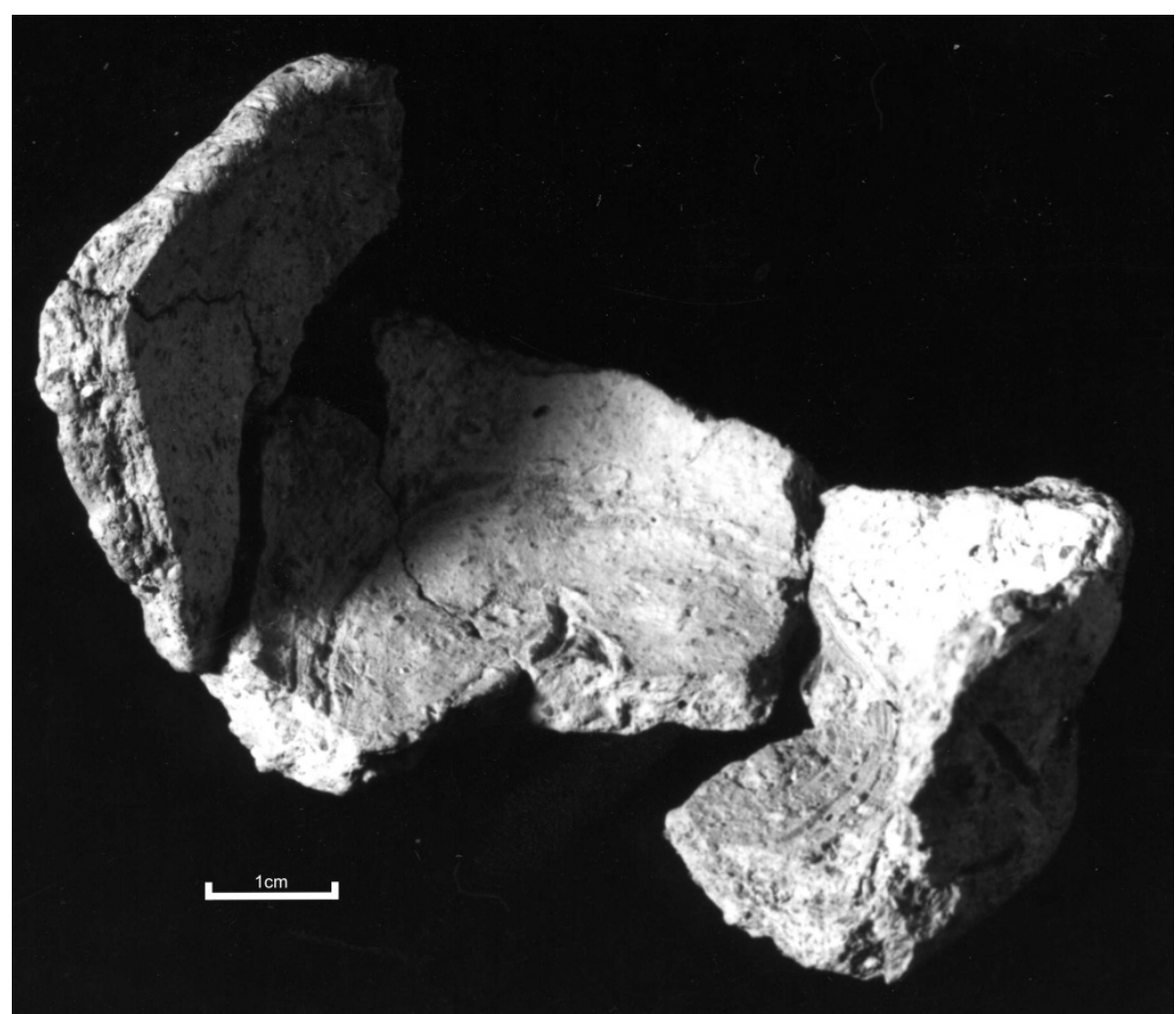

Figure 10. Pottery fragment (vessel \#2).



Figure 11. Adze Cave showing approximate location of adze finds (map redrawn from original held at the Queensland Museum). 
continued to a depth of about $15 \mathrm{~cm}$. Coarseness of the deposit increased with depth and at the base the $>6 \mathrm{~mm}$ sediment constituted more than $50 \%$ of the weight of the deposit. No cultural material or evidence of occupation was found and excavations ceased at this point. There was no evidence of faunal remains and, apart from the charcoal on the surface which may have derived from the dump, there was no evidence of fires. Given the sterile nature of the excavated deposit, no radiocarbon dates were obtained.

\section{Adze Blades}

Three polished stone adze blades were recovered from Adze Cave in 1985 (Coleman nd-a:67). Two were donated to the Queensland Museum while the third remains unaccounted for. Further inspection of the cave during the 1990 field season revealed a fourth adze (see above) which is also housed in the Queensland Museum (Figures 12-14). Coleman has previously suggested that these adze blades were of Melanesian origin and are 'stylistically the same and are a type common in New Guinea and throughout Indonesia/S.E. Asia into the Southwest Pacific' (Coleman nd-a:68).

Two of the adzes were examined by geoscientist Friedrich von Gnielinski in an attempt to source the stone used in their manufacture. In his notes held at the Queensland Museum, Von Gnielinski described the adzes as:

- Adze \#S861/5: Very fine-grained ephyritic light-tomedium grey volcanic, epidochlorite alteration. Heavily altered volcanic or veined material similar to ore veins on Horn Island.

- Adze \#S861/2: Fine-grained ephyritic volcanic, epidichlorite alteration, some quartz or feldspar crystals, secondary weathering, iron concretion. Similar to rock from Horn Island.

The sourcing results reveal similar outcomes to other sourcing projects involving stone implements (e.g. gabagaba [stone-headed clubs], and Kiwai-'type' stone axes) collected from or provenanced to Torres Strait and southwest Papua New Guinea. McNiven and von Gnielinski's research revealed that the raw materials used for the majority of these stone implements originated from Torres Strait islands such as Dauan, Mua, Badu, Gebar and Ngurupai (Horn Island) (Hitchcock 2004; McNiven 1998; McNiven and von Gnielinski 2004, 2008; McNiven et al. 2004a). As McNiven (1998:107) recently pointed out, these results contradicted the early ethnographic literature which indicated that stone implements were traded or imported from southern Papua New Guinea (an area devoid of stone) to Torres Strait where there are abundant sources for tool stone. McNiven (1998:107) suggested that this paradox 'resulted from the movement of these items backwards and forwards between hostile groups by means of looting and ceremonial exchange'.

The Ngiangu adzes represent another example of stone tools whose raw material has been sourced to Torres Strait. Although a stone artefact quarry has yet to be recorded on Horn Island, the sourcing results here (and from McNiven and von Gnielinski's ongoing research) indicates that some stone tool manufacture did, most likely, occur in the Kaurareg Archipelago (see also Moore 1973, 1986). Interestingly, the Ngiangu stone implements did not end up far from their probable original source, although it remains unknown whether the adzes were used in ceremonial exchange or for other social purposes. While the sourcing of the raw material used in the manufacture of the Ngiangu adzes has assisted in reassessing earlier inferences regarding a Melanesian origin for the stone adzes, we have been unable to verify Coleman's suggestion of a Southeast Asian/Southwest Pacific stylistic similarity.

Given the small size of the shelter and the restricted living space, it is unlikely that Adze Cave provided more than temporary shelter. In the absence of evidence of occupation in the deposit, the cultural material that was found in the shelter (four adzes, two quartz pebbles and a flake) appears to represent a cache. Caching of artefacts is not unknown in Torres Strait with objects such as turtle shell mask fragments being recovered from the surface of a small cave at Ikis on Badu in 2001 (David et al. 2004c). However, given the disturbance of the deposit, it is not possible to determine if they had been originally buried a strategy commonly associated with the caching of stone artefacts in some areas of Aboriginal Australia (Hiscock 1988). There is little material to assist in constructing a scenario to account for this group of artefacts; all we can suggest at present is that the manufactured adzes were transported and placed in this small, unoccupied shelter at some point in the recent past during a periodic visit to this satellite island. Whether they were intended for trade or other social purpose remains unknown. Nevertheless, the context, the number, and character of the adzes is unique in Torres Strait, and suggests they may have been part of a cache.

\section{Excavation - Fern Cave (1990)}

The aim of this investigation was to determine if the cave deposits had a significant cultural signature to them that would provide an indication of antiquity of occupation or the type of cultural activities that may have been undertaken in conjunction with the production of rock art.

A $50 \mathrm{~cm} \times 50 \mathrm{~cm}$ test pit was located approximately $10 \mathrm{~m}$ from the rear of the cave (see below for full description of cave) on the high point of a gently northeasterly sloping deposit (Figures 15-16). Two metres to the north and east of the pit are a number of large roof-fall boulders. The deposit around these boulders has been significantly eroded. A mat of lichen has formed on the surface of the deposit and all the surrounding boulders. Rock art is located on the surface of all the walls facing the excavated area (see below).

The pit was excavated with a trowel and brush in volumetrically standard units (bucket spits) of about $2 \mathrm{~cm}$ in thickness to a mean depth of $50 \mathrm{~cm}$ when bedrock was encountered. The deposit was sieved through $3 \mathrm{~mm}$ and $6 \mathrm{~mm}$ sieves. It consisted of a mixture of coral sand, shell hash and coral rubble. The upper $22 \mathrm{~cm}$ comprised a banded deposit of six well-defined layers ranging from very pale brown (10YR 8/4) to yellow (10YR 7/8 and 10YR 7/6) and reddish-yellow (10YR 7.5 6/6, 7/6 and $6 / 8$ ). Immediately beneath these was a uniform deposit of weathered coral rubble with increasing sand fraction and noticeable silicification. A small number of water-worn pebbles were noted between 45 and $50 \mathrm{~cm}$ while the lower 

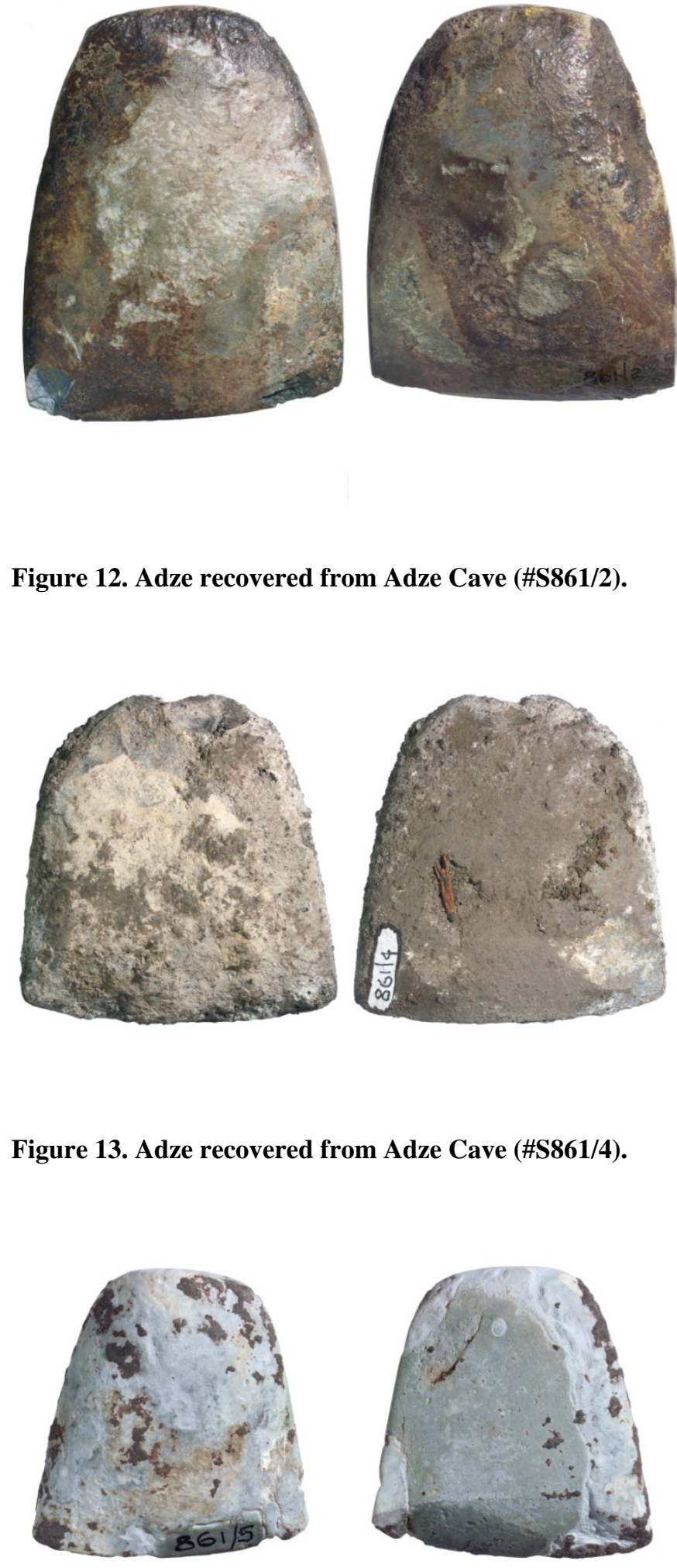

Figure 13. Adze recovered from Adze Cave (\#S861/4).

Figure 14. Adze recovered from Adze Cave (\#S861/5).
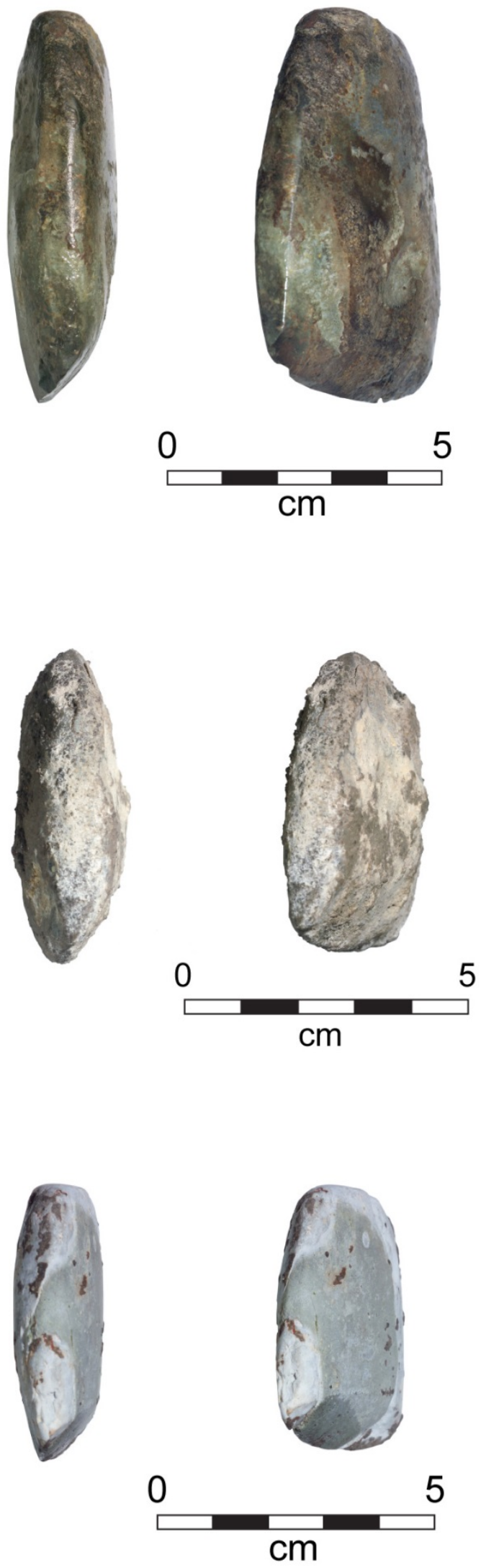


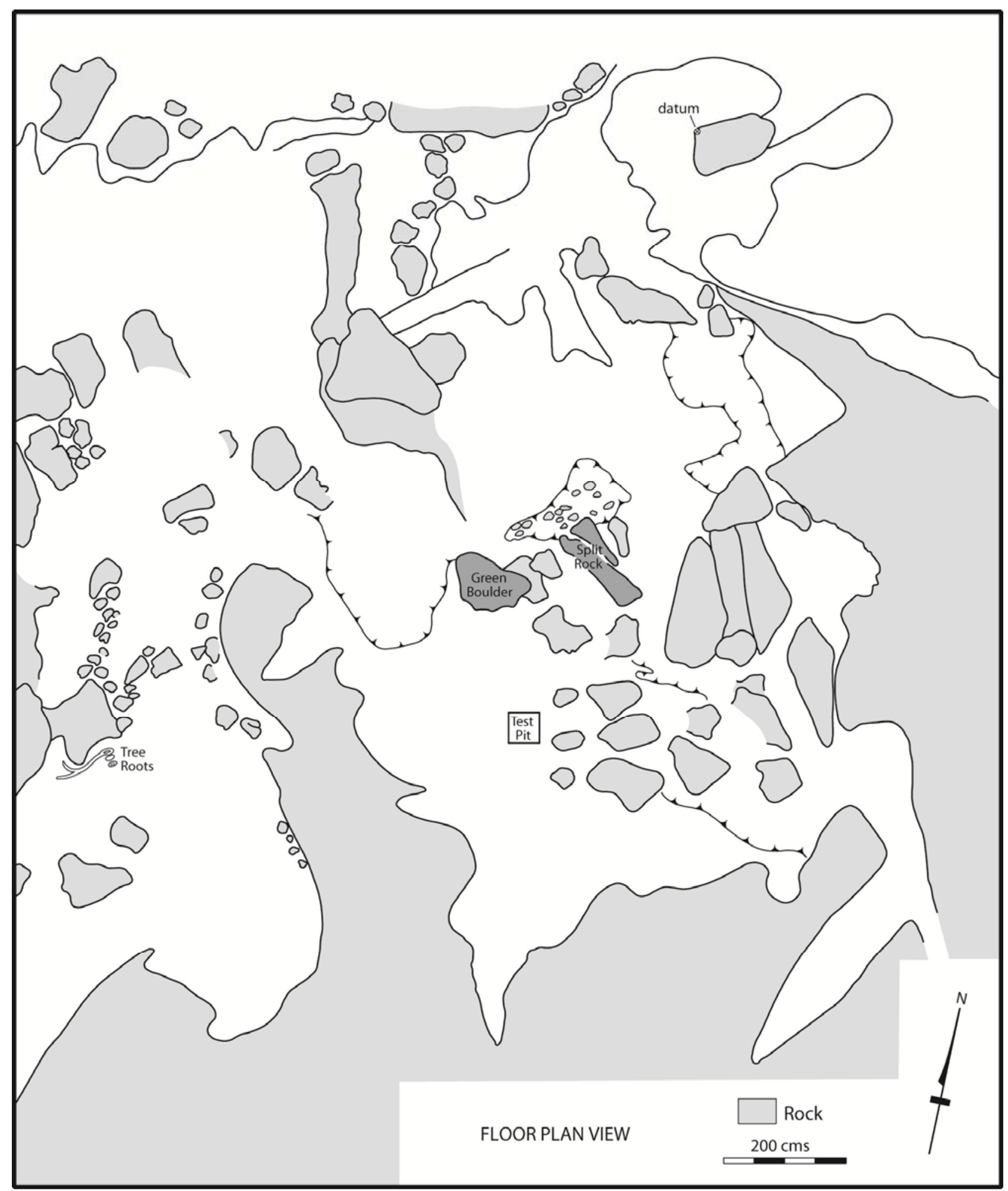

Figure 15. Plan view of Fern Cave (map redrawn from original held at the Queensland Museum). 


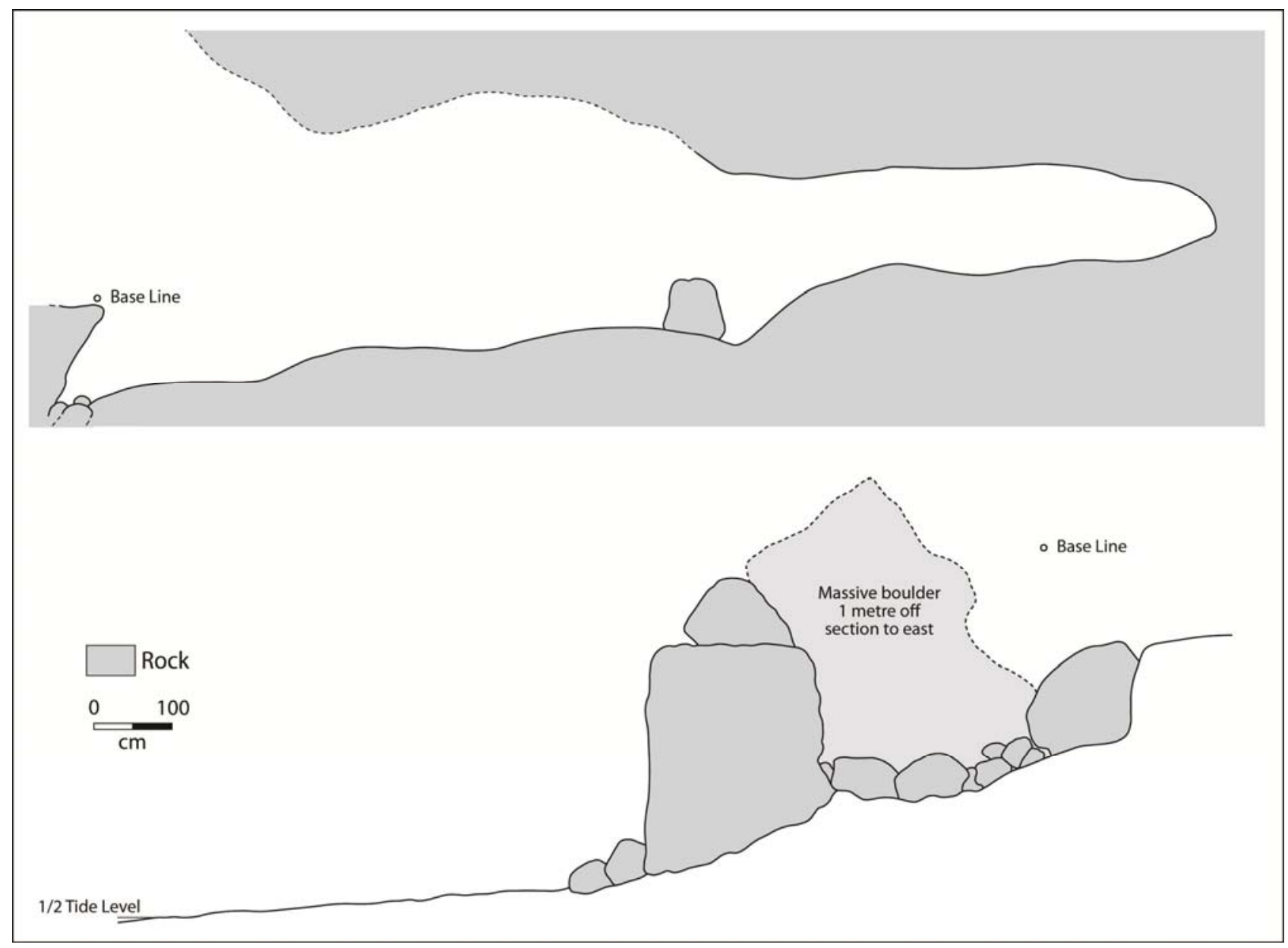

Figure 16. Cross-section views of Fern Cave (map redrawn from original held at the Queensland Museum).

$10 \mathrm{~cm}$ contained bedrock fragments of a light-coloured appearance. No cultural material or evidence of cultural activities (artefacts, charcoal, hearths or culturally-derived shell) was found in the deposit and thus no radiocarbon dates were obtained. The character of this deposit was consistent with one derived from a series of storm events introducing material derived from the fringing coral reefs.

That both excavations on Ngiangu proved sterile restricts our ability to adequately understand and evaluate Ngiangu's position within the known periods of cultural transformations that were taking place across the Strait at c.3800-4000 BP, c. 2600 BP, c.600-800 BP and c.300400 BP (e.g. Barham 2000; Carter 2004; Crouch et al. 2007; David et al. 2005; David and Mura Badulgal 2006; David et al. 2009; McNiven and Feldman 2003; McNiven 2006; McNiven et al. 2006; McNiven et al. 2009b). Although there is no visible evidence for any long-term occupation, surface materials and rock art (below) do indicate an ephemeral presence. While the sea must be considered an inhibiting factor (e.g. tidal and storm surge) towards the survival of any cultural material, future investigations on the island should continue to target the various caves scattered around the island in an effort to obtain some chronological indicators of island use.

\section{Rock Art}

Although Torres Strait rock art was first documented in 1888 by Alfred Haddon at Kirriri, Ngiangu's rock art remained unrecorded until the Queensland Museum's comprehensive recording programme began in 1985 (see
McNiven and David 2004 for an overview of rock art research in Torres Strait prior to 2000; see also Brady 2005).

\section{Recording Methodology}

Coleman (1991:4) described the Queensland Museum's recording procedure for rock paintings, historical writing, and site context as consisting of:

The painting areas were gridded with temporary registration targets and approximately 1,400 colour photographic frames using the $2 \frac{1}{4}$ square format were taken utilizing professional studio lighting techniques. Floor plans, floor and roof contours, and representative sections of caves were recorded using a laser level, theodolite and alidade. Additionally, XYZ co-ordinates of individual paintings were recorded relative to datum using theodolite and tape ... Direct tracings were taken of selective images. The geological nature of the caves, their exposure to weather and sea, their internal environment, and the natural and human aspects which have and will continue to contribute to the deterioration of the paintings was examined and noted.

In 2003 the photographic slides were scanned at high resolution and subjected to computer enhancement as a means to increasing the visibility of the faded images (see Brady 2006; David et al. 2001 for details on enhancement procedures for Torres Strait rock art). Ngiangu's rock art represents the first instance in Torres Strait whereby computer enhancement techniques were applied to rock art that was not digitally photographed. 


\section{Locations, Rock Art and Motif Classification}

The Queensland Museum Expedition documented a total of 152 monochrome and bichrome paintings (incorporating a range of colours including red, white, mulberry, blue and black) from four shoreline caves: Fern Cave, Post Office Cave, Pouri Pouri Cave and Mystery Man Cave. Whereas previous discussions of Ngiangu's rock art (e.g. Brady 2005; Brady and Kaurareg Aboriginal Community 2007) have treated the island's rock art assemblage as a single unit (arising from a lack of data attributing specific motifs to individual caves) previously overlooked data stored at the Queensland Museum and from Coleman's estate has shed new light on the exact locations of the rock paintings from within the four caves. This new material allows for a more fine-grained analysis into the island's rock art including addressing questions such as variability between caves. Descriptions of the four shoreline rock art caves are compiled from Coleman (nda, nd-b, 1991) and unpublished data (plan and profile drawings) from the Queensland Museum Expedition. Overall the condition of the rock paintings varies from good to heavily deteriorated with the majority of damage related to water runoff.

Ngiangu's motifs have been classified hierarchically by Brady (2005) at four different levels as part of the broader Torres Strait region rock art classification scheme (see Brady 2005 for further details). The four levels (in hierarchical order) are:

- Determinate/indeterminate

- Figurative/non-figurative

- Group motif form

- Specific motif form

\section{Fern Cave}

Fern Cave is the largest cave on the island and consists of an open rockshelter containing several smaller caves and crevices; the bulk of the non-European rock art is located in this cave (Coleman nd-a, 1991) (Figures 15-17). The ground surface of the cave extending to the rear wall is littered with coral rubble and boulders of varying sizes which 'have been rounded by water action' (Coleman nda:69). The cave is approximately $17 \mathrm{~m}$ deep and the only cultural materials located in the cave consist of European contact items such as hoop iron from casks, bottle glass fragments and animal bone (probably pig) (Coleman ndb:9).

A total of 113 images (98 determinate and 15 indeterminate pictures) were identified by LMB from the Queensland Museum slides from Fern Cave (Figure 20). Determinate images were divided into eight figurative $(8.2 \%)$ and 90 non-figurative $(91.8 \%)$ pictures. Of the figurative paintings, zoomorphs (a combination of marine and terrestrial animals) are most common $(\mathrm{n}=6)$. A dari (traditional Torres Strait headdress) (Figure 18) and an outlined anthropomorph with a headdress were also documented. Non-figurative imagery consisted of a widerange of open geometric (e.g. curved lines, arrows, straight lines, parallel lines, V-shape variants), enclosed geometric (e.g. circle variants, triangle variants, crescent variants, oval variants) and linear non-figurative pictures (e.g. extended linear, complex linear, central line shapes (Figure 19), and non-geometric comb shapes (Figure 21). Fern Cave features an unusually high frequency of

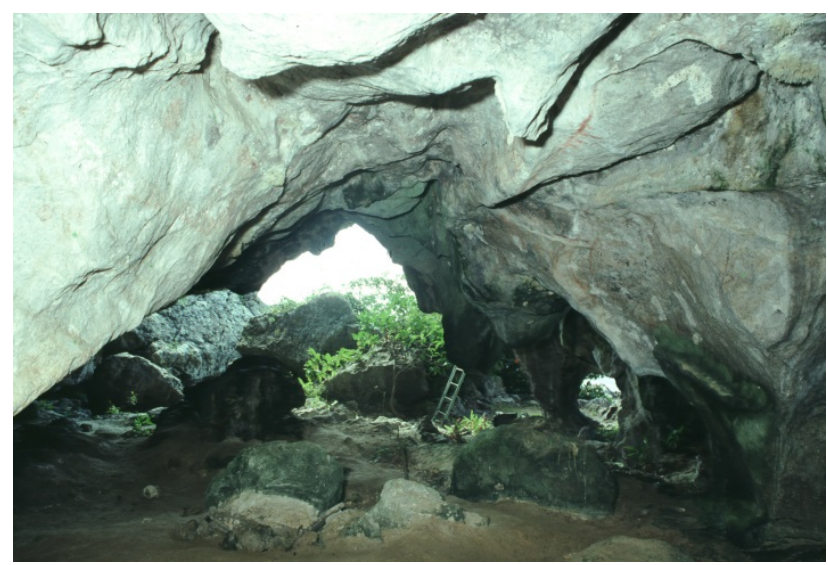

Figure 17. View from the interior of Fern Cave towards the entrance.

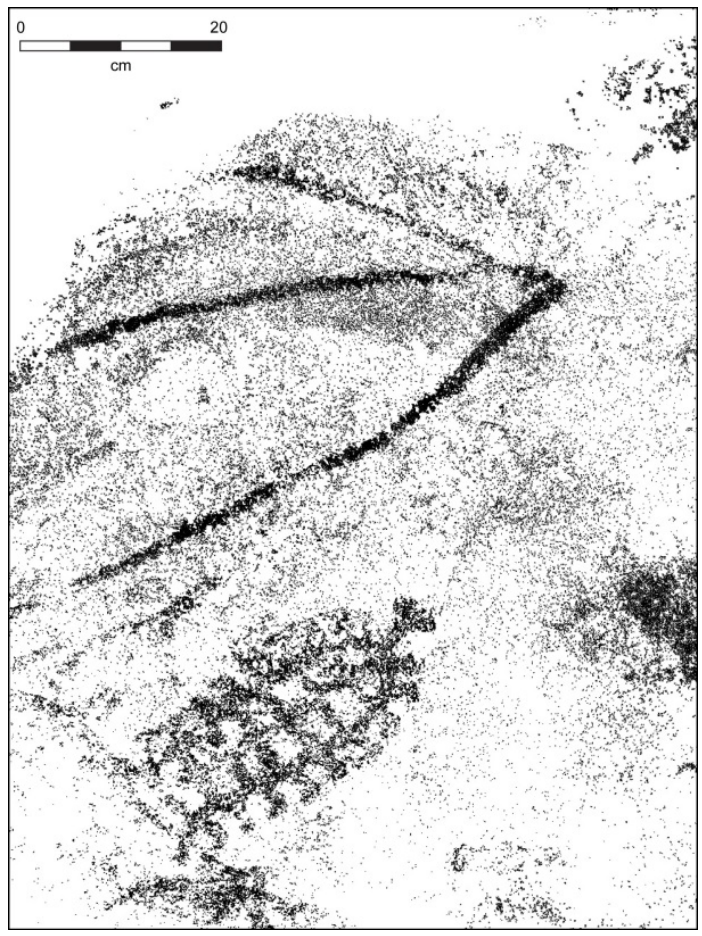

Figure 18. Fern Cave: black and white conversion of a dari and arrow.

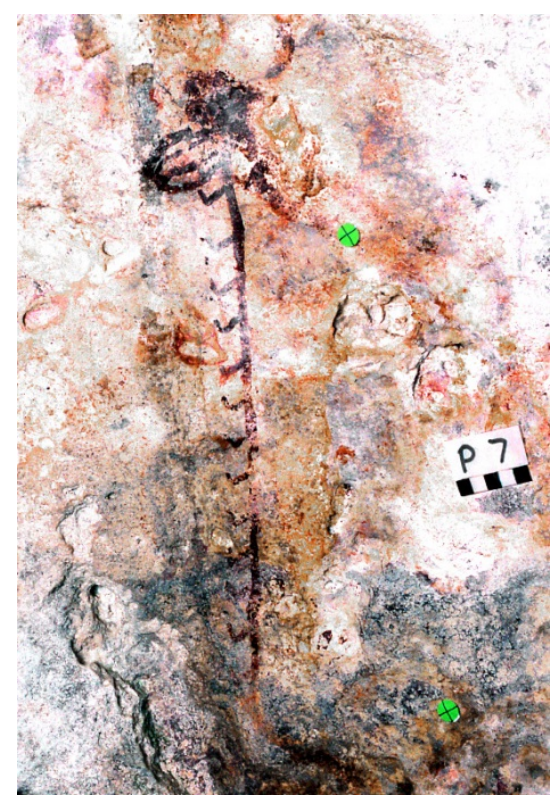

Figure 19. Fern Cave: computer enhancement of a central line shape. 


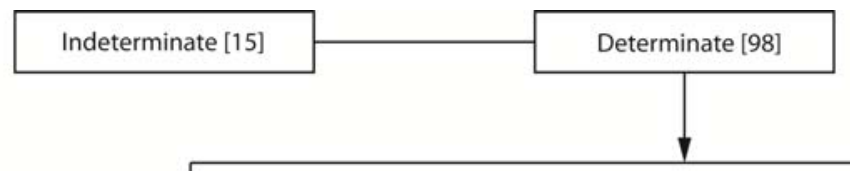

L2

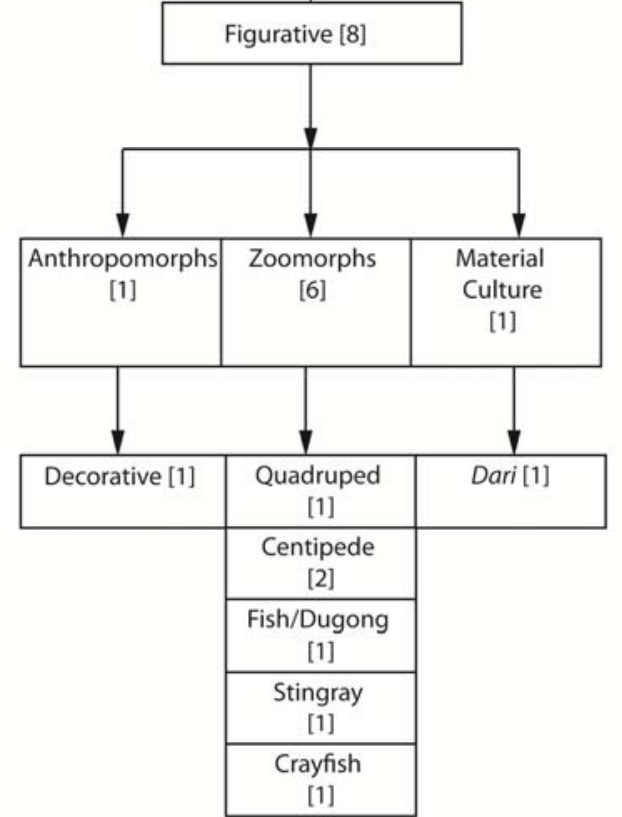

Figure 20. Fern Cave motif classificatory scheme.
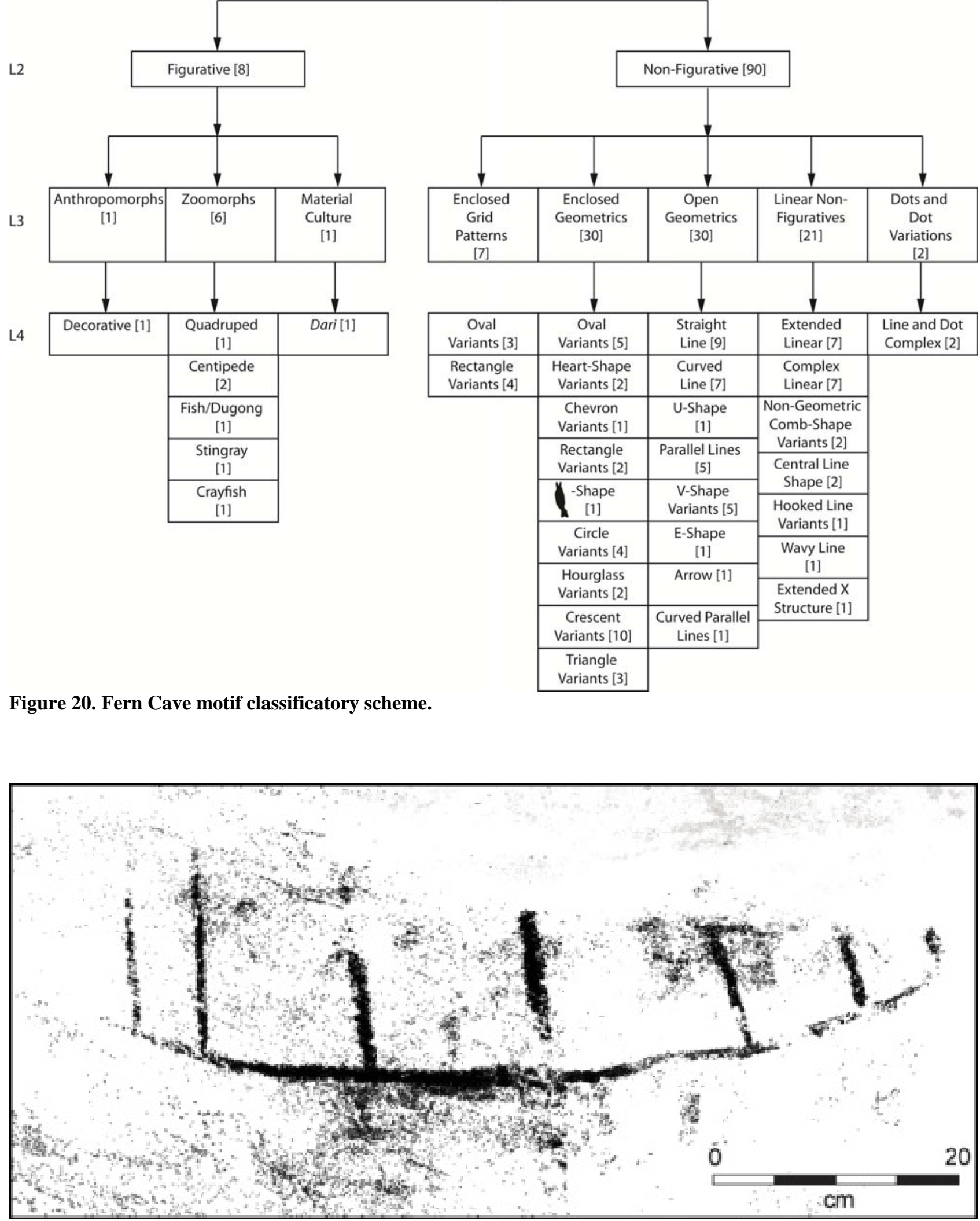

Figure 21. Fern Cave: black and white conversion of a non-geometric comb-shape variant. 


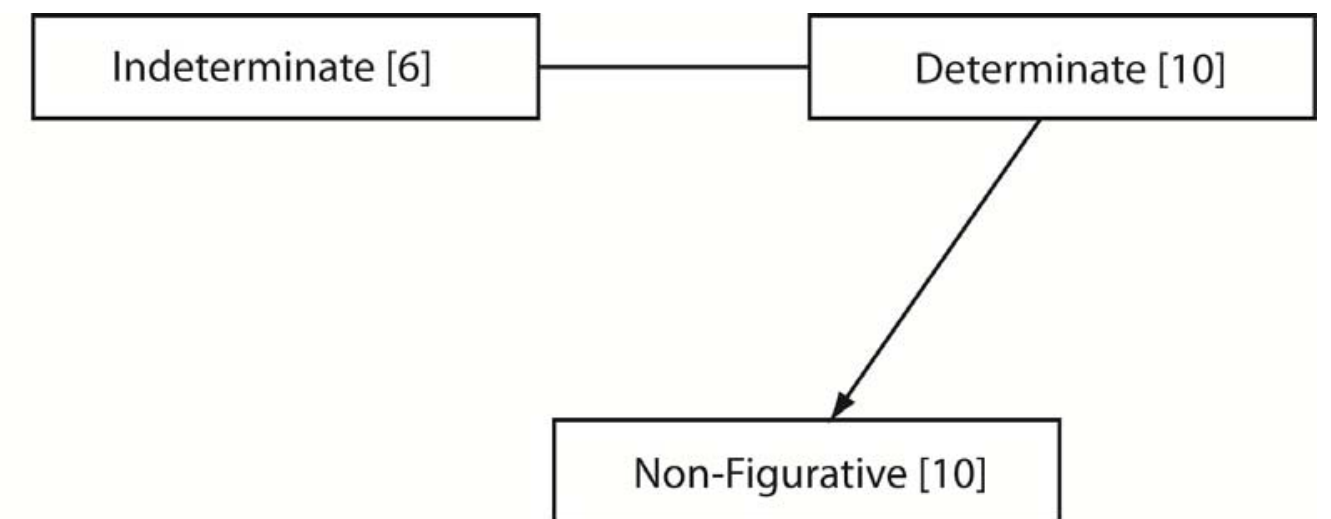

$\mathrm{L} 2$

Non-Figurative [10]

L3

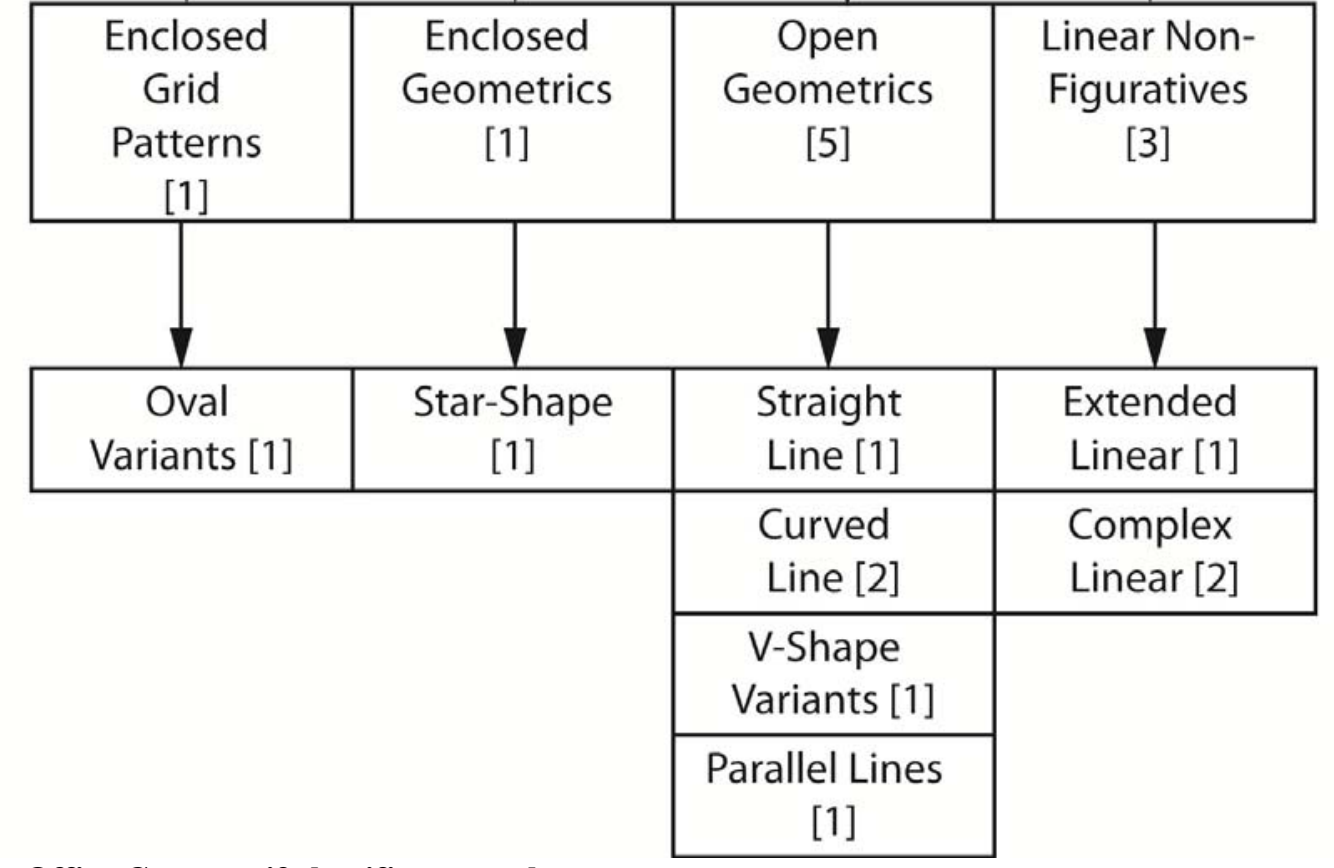

Figure 22. Post Office Cave motif classificatory scheme.

enclosed grid patterns $(n=7)$, rectangle variants and oval variants when compared to the other rock art caves on Ngiangu and, indeed, the rest of Torres Strait region rock art (Brady 2005). No superimpositions were recorded from the cave. While red is the dominant colour of the rock paintings here, one black and several mulberrycoloured images have also been documented.

\section{Post Office Cave}

There is a surprising lack of descriptive information about Post Office Cave and its rock art given its significant role in the early European maritime history of the region (Delaney 1990). The cave is approximately 20m deep and $12 \mathrm{~m}$ at its widest point and features several extensions from the main area. Coleman (nd-b:6) notes that natural light does not penetrate beyond $16 \mathrm{~m}$. Small- and mediumsized rocks are scattered across the ground surface. A large tree trunk dominates the entrance to the cave. The site lies $4 \mathrm{~m}$ above the Half Tide Mark and the entrance is guarded by a steep overhang. The Queensland Museum team documented rock paintings from the walls and ceiling of the cave.

A total of 16 rock paintings (10 determinate and 6 indeterminate) were identified by LMB (Figure 22). No figurative paintings were recorded from the cave. The majority of images are open geometrics (e.g. parallel lines, straight lines, curved lines) while smaller numbers of enclosed grid patterns (oval variant, Figure 23), linear non-figuratives (e.g. complex linears), and enclosed geometrics (star shapes) were noted. In many instances, historical writing has been superimposed over the rock paintings. Only one case featured a superimposition not involving historical writing: a small red complex linear design has been placed directly over a larger blue complex linear design (this is the only instance where another colour other than red was recorded in a rock painting from the cave) (Figure 24). 


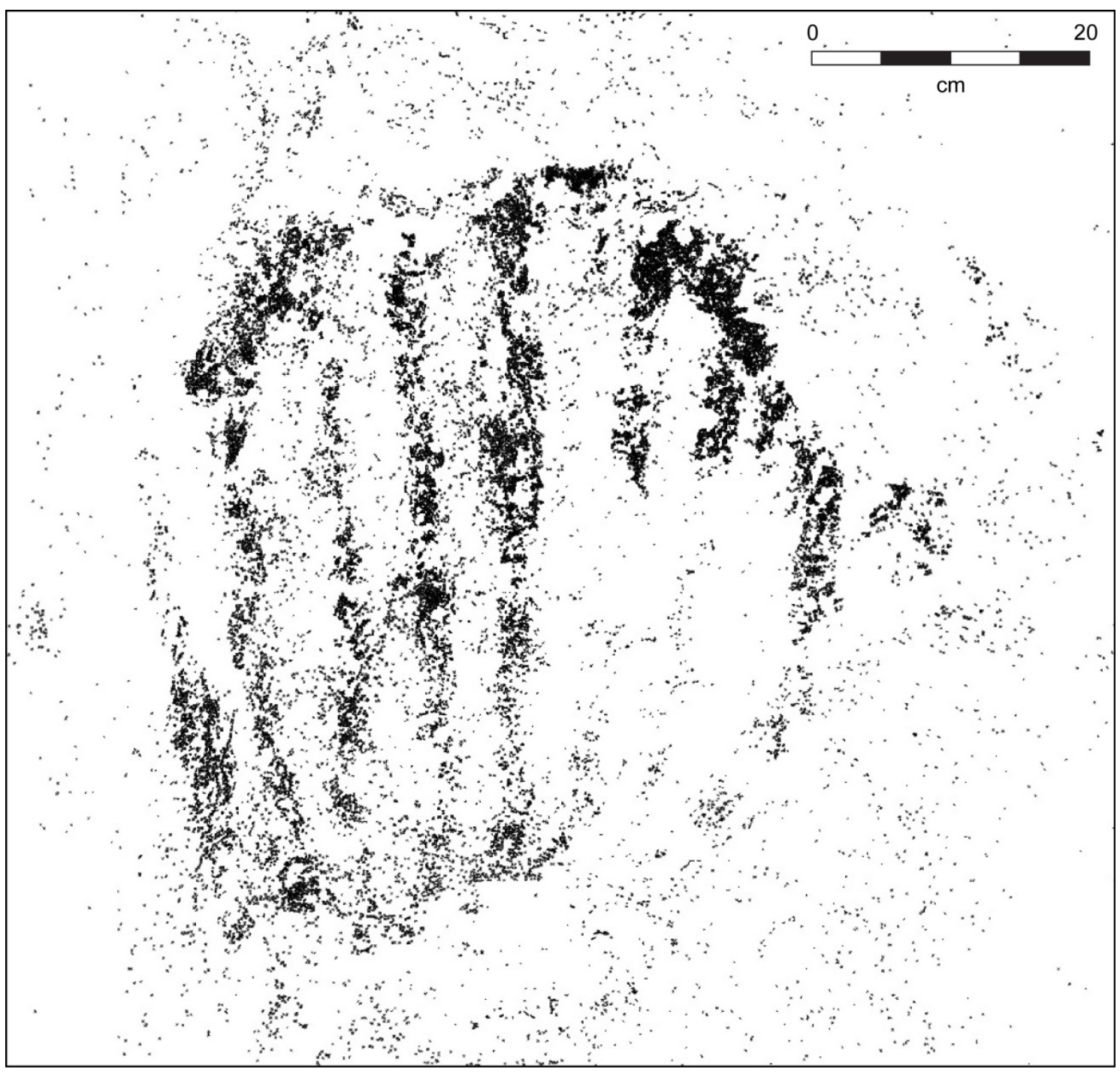

Figure 23. Post Office Cave: black and white conversion of an enclosed grid pattern (oval variant).

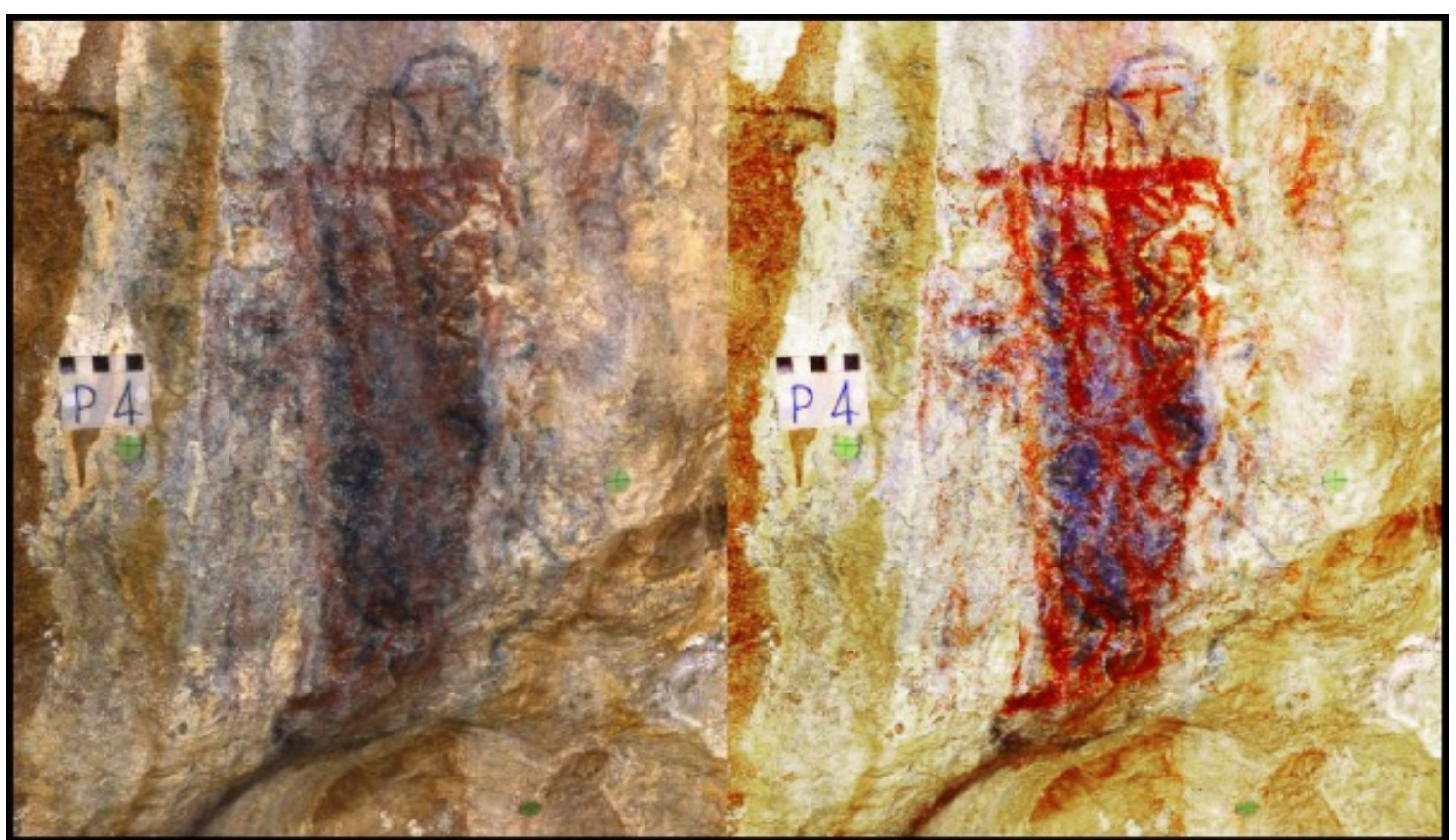

Figure 24. Post Office Cave: computer enhancement of a small red complex linear design superimposed over a larger blue complex linear design. 


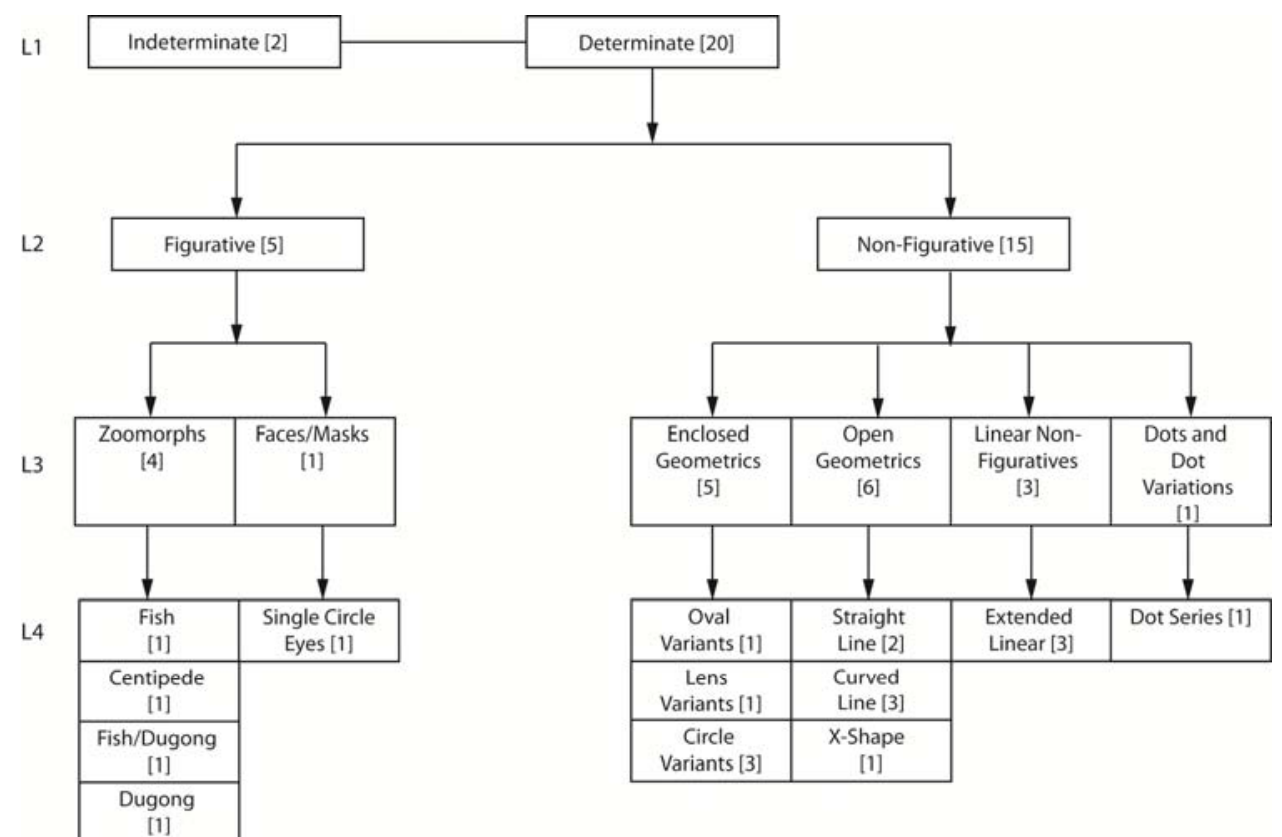

Figure 25. Pouri Pouri Cave motif classificatory scheme.

\section{Pouri Pouri Cave}

Only a brief description of Pouri Pouri cave is provided by Coleman (nd-b). He describes the site as a small, single-chambered cave 'located in the western wall of the boat ramp cutting' (Coleman nd-b:6). The cave measures $4 \mathrm{~m}$-deep with a $2 \mathrm{~m}$-wide entrance and an entrance height of $1.6 \mathrm{~m}$. Two patches of cemented sand are located adjacent to the north and south sides near the rear of the cave. Coleman (nd-b:6) notes that paintings were recorded on the side walls of the cave and have been damaged by historical writing, most likely occurring as a result of the military occupation of the island during World War II (see Delaney 1990).

The cave contains 22 paintings -20 determinate and two indeterminate (Figure 25). Figurative imagery is minimal with four zoomorphs (terrestrial [e.g. centipede, Figure 26] and marine animals such as dugong and fish) and one face/mask (Figure 27). Non-figurative paintings are composed primarily of open geometrics (e.g. straight lines, X-shapes, curved lines), enclosed geometrics (e.g. circle variants, oval variants) and linear non-figuratives (e.g. extended linear). All images are painted monochrome red save one - a red circle variant with small infilled red triangle shapes positioned around the perimeter of the circle and framed in a white pigment. The only superimpositions evident are where historical writing has been placed over the rock paintings.

\section{Mystery Man Cave}

Mystery Man Cave is situated in a cavity in a north-facing cliff at the southern end of the beach and is described as 'nothing more than where two vertical, very narrow clefts or crevices come together a few centimetres behind the rock face and share a common opening at the face itself' (Coleman nd-a:66). The cave is approximately 6m-deep and narrows towards the rear. The entrance lies $35 \mathrm{~m}$ upslope from the Half Tide Mark, while the entrance height is roughly $3 \mathrm{~m}$. The ground surface of the first $2.5 \mathrm{~m}$ of the cave is scattered with small boulders.

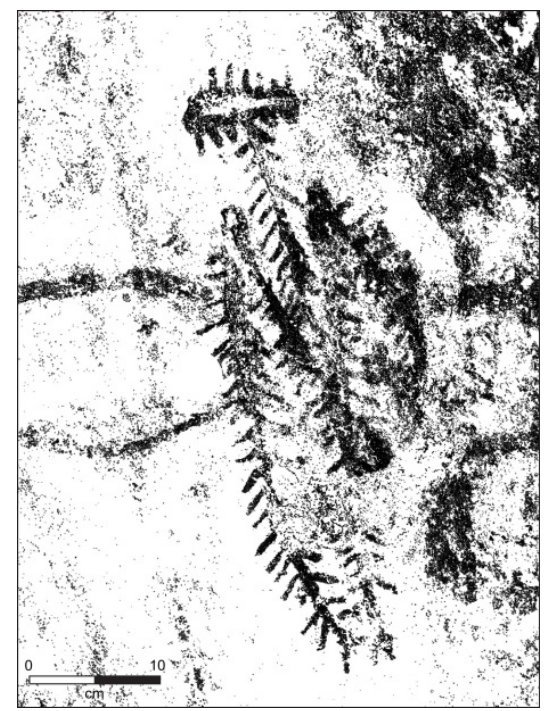

Figure 26. Pouri Pouri Cave: black and white conversion of a centipede.

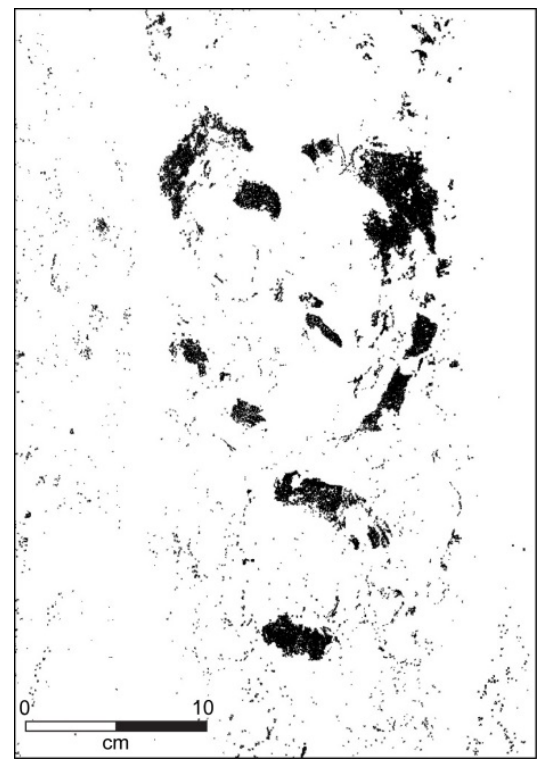

Figure 27. Pouri Pouri Cave: black and white conversion of a face/mask. 


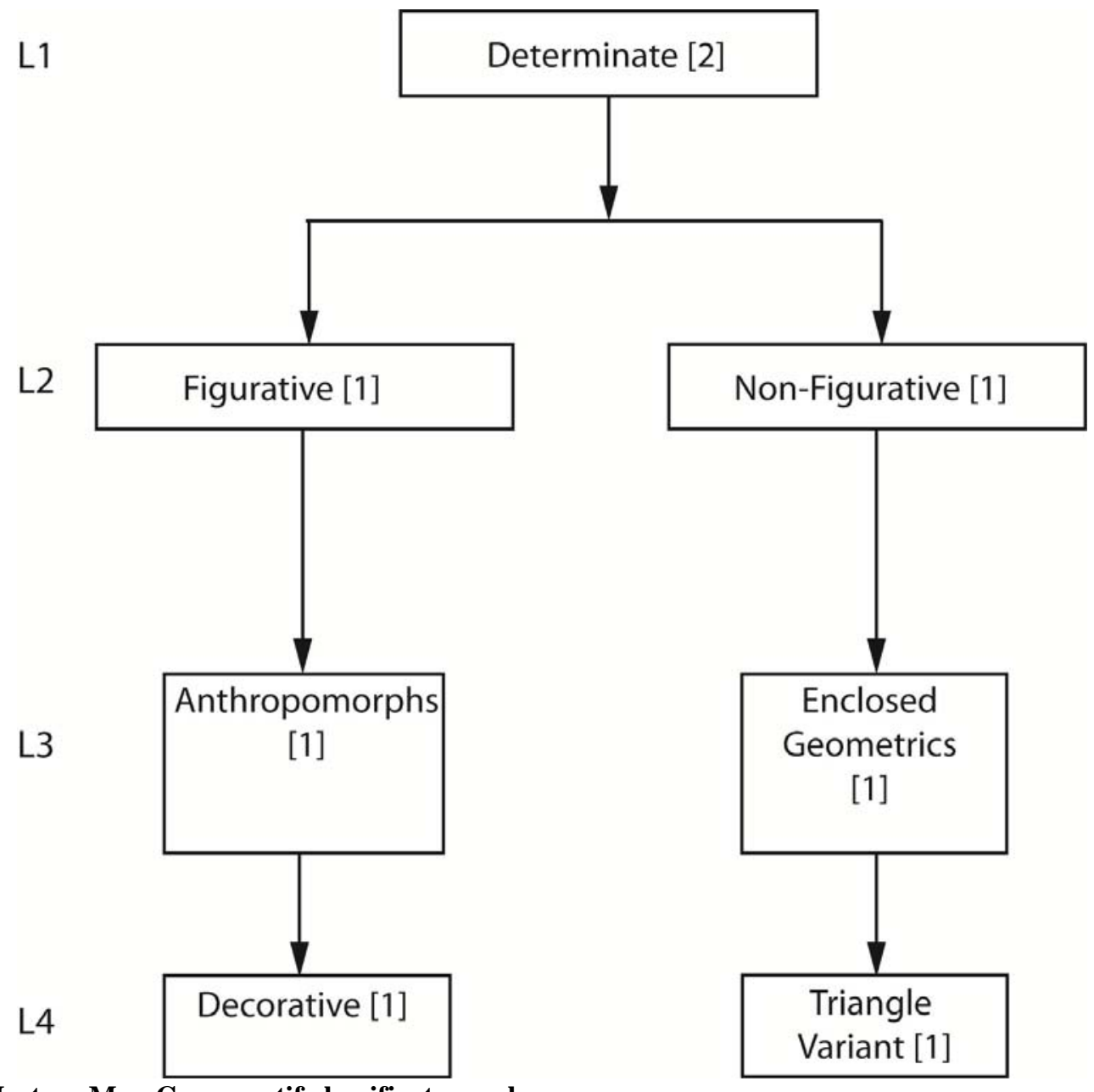

Figure 28. Mystery Man Cave: motif classificatory scheme.

Only two red determinate rock paintings were recorded from the side wall of the cave (Figure 28) - a large outlined anthropomorph, and an enclosed geometric (triangle variant) positioned to the left of the anthropomorph's head (see Figure 33 below).

\section{Discussion}

Discussion of Ngiangu's rock art is carried out at four levels: (1) variation between caves; (2) the assemblage as a discrete island unit; (3) regional comparisons involving Ngiangu's rock art, other Torres Strait region rock art, and decorated material culture and scarred designs from Torres Strait, Cape York, and southern Papua New Guinea; and (4) reassessment of earlier interpretations of motifs.

\section{Variation between Caves}

The most obvious variation is the number of motifs recorded from each cave. Fern Cave is clearly where the bulk of rock painting activity was undertaken with images here accounting for $74.3 \%$ of the entire assemblage. Smaller numbers of motifs have been recorded from Post Office (10.6\%) and Pouri Pouri (13.8\%) caves indicating they were also well-known places for painting activity. Mystery Man Cave features the lowest number of rock paintings ( $\mathrm{n}=2$, or $1.3 \%$ of the entire assemblage). Based on the lack of differential weathering between the two documented motifs it is likely this cave was probably only used for one episode of painting. However, it should be noted that the extensive historical writing (especially in
Post Office and Pouri Pouri caves) produced since the mid-1800s has most likely obscured other motifs.

Apart from Mystery Man Cave, non-figurative imagery dominates with figurative motifs either absent (Pouri Pouri Cave) or occurring in very low frequency and usually depicting zoomorphs (both marine and terrestrial animals; zoomorphs account for $71.4 \%$ of figurative motifs). Additionally, there appears to be little differentiation in the non-figurative imagery with open geometrics, enclosed geometrics and linear non-figurative pictures dominating Fern, Post Office and Pouri Pouri caves. Consequently, these patterns reveal little variation between caves in terms of general motif trends.

Some motifs are endemic to particular caves. For example, Fern Cave features the only crescent variants anywhere on the island -10 outlined crescent variants have been recorded in four clusters: three clusters of two crescent variants each (one cluster containing two small dots in the middle of each shape), and one cluster of four crescent variants (Figure 29). In addition, the dari headdress is found only in Fern Cave, while the lone face/mask is documented in Pouri Pouri Cave. Fern Cave features a distinctive form of centipede drawn in rectangular sections (see below). Enclosed grid patterns are a rare form of motif from Torres Strait. However, seven of eight known enclosed grid patterns are located in Fern Cave (Figure 30). These examples indicate that some motifs were not as prevalent elsewhere across the island and were geographically restricted to only one cave. 


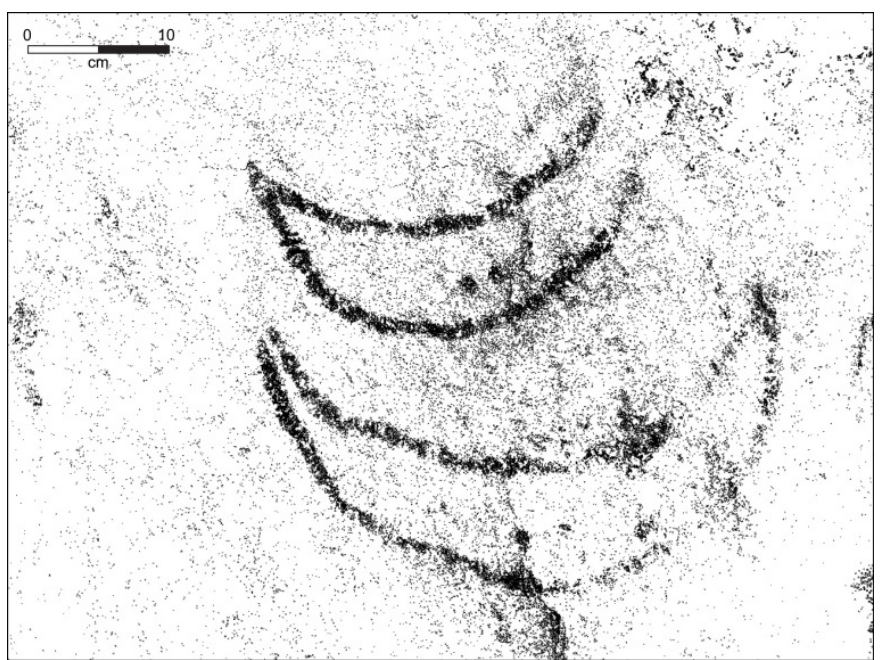

Figure 29. Fern Cave: black and white conversion of two crescent variants.

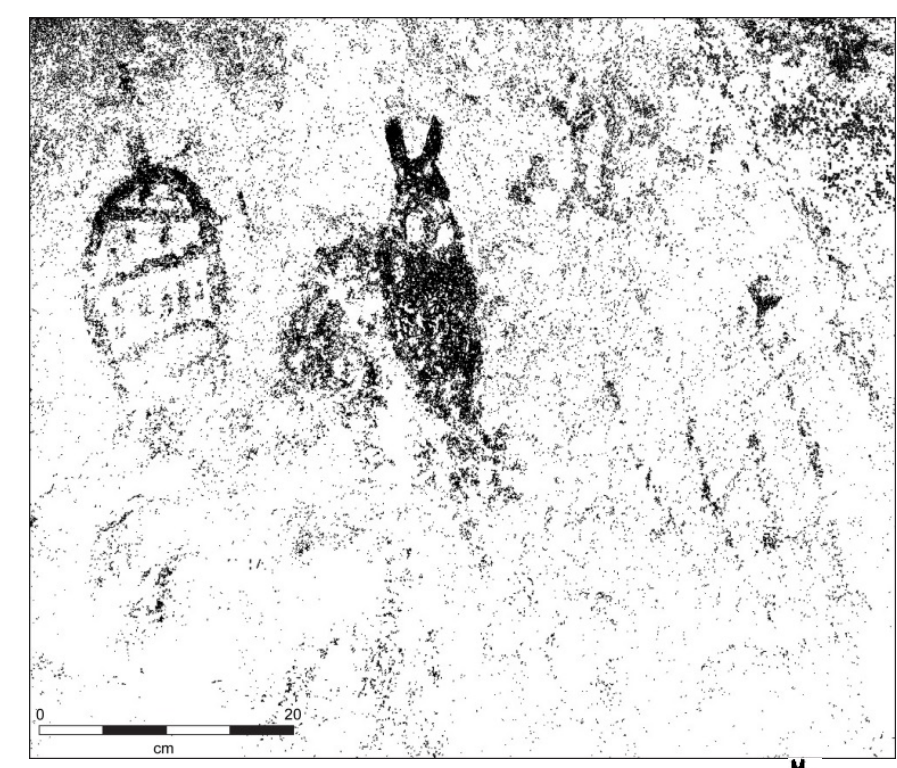

Figure 30. Fern Cave: black and white conversion of an enclosed grid pattern, $\lambda$-shape, and parallel lines.

\section{Ngiangu as an Island Unit}

Analysis of the complete rock art assemblage from Ngiangu reveals a clear predominance of non-figurative imagery (89.2\%), with figurative pictures constituting only $10.8 \%$ of all pictures (Table 1 ).

An examination of geometric pictures (enclosed and open) compared with the rest of the non-figurative group motif forms (enclosed grid pattern, linear non-figuratives and dots and dot variation) reveals a trend towards the depiction of geometric pictures with $67.2 \%$ of Ngiangu's non-figurative pictures classified as open and enclosed geometrics (Table 2).

Ngiangu rock paintings feature several colours indicating that several pigment types were being exploited (Table 3). For the first time in Torres Strait rock art, the colours black (Fern Cave), mulberry (Fern Cave), white (Pouri Pouri, as part of a bichrome image incorporating red) and blue (Post Office Cave), have been recorded; blue being one of the rarer colours used in the production of rock art (Cole and Watchman 1993).

Computer enhancement of the scanned slides was used to identify a small number of extra paintings which could not be identified with the naked eye $(n=3$, or $2.3 \%$ of Ngiangu's pictures); many other rock paintings had their design elements clarified using this process.

Clues concerning the antiquity of Ngiangu's rock art are, at present, unavailable. No direct dating of the paintings has as yet been undertaken. There are no other recordings of the paintings that can be used for comparative purposes. Additionally, no excavations were carried out below painted panels to recover buried ochres. The lone super-impositioning involving rock paintings (recorded from Post Office Cave) provides minimal insight into time difference between the execution of the two paintings given the little difference in the clarity of the two images. Additional super-impositioning of historical writing over many faded rock paintings indicates that some images were produced prior to European contact, and the differential weathering also suggests considerable time had passed between the Indigenous and European episodes of inscription. Speculation concerning the antiquity of the paintings is based on the aforementioned harsh coastal climate and proximity of the caves to the sea. These conditions are unlikely to provide suitable circumstances for the preservation of the paintings for more than a few hundred years. 
Table 1. Ngiangu, Level 2 figurative/non-figurative paintings.

\begin{tabular}{|l|r|r|}
\hline \multicolumn{1}{|c|}{ Motif Type } & \# of Pictures & \% of Total \\
\hline Figurative & 14 & 10.8 \\
\hline Non-Figurative & 116 & 89.2 \\
\hline Total & 130 & 100 \\
\hline
\end{tabular}

Table 2. Distribution and frequency of group motifs.

\begin{tabular}{|c|c|c|c|c|c|}
\hline Level 3 - Group Motif & Fern Cave & Post Office Cave & Pouri Pouri Cave & Mystery Man Cave & Total \\
\hline \multicolumn{6}{|c|}{ Figurative Motifs } \\
\hline Palm Trees & 0 & 0 & 0 & 0 & 0 \\
\hline Anthropomorphs & 1 & 0 & 0 & 1 & 2 \\
\hline Faces/Masks & 0 & 0 & 1 & 0 & 1 \\
\hline Zoomorphs & 6 & 0 & 4 & 0 & 10 \\
\hline Material Culture & 1 & 0 & 0 & 0 & 1 \\
\hline Figurative Total & 8 & 0 & 5 & 1 & 14 \\
\hline \multicolumn{6}{|c|}{ Non-Figurative Motifs } \\
\hline Enclosed Grid Patterns & 7 & 1 & 0 & 0 & 8 \\
\hline Enclosed Geometrics & 30 & 1 & 5 & 1 & 37 \\
\hline Open Geometrics & 30 & 5 & 6 & 0 & 41 \\
\hline Linear Non-Figuratives & 21 & 3 & 3 & 0 & 27 \\
\hline Dots \& Dot Variations & 2 & 0 & 1 & 0 & 3 \\
\hline Infilled Non-Geometrics & 0 & 0 & 0 & 0 & 0 \\
\hline Non-Figurative Total & 90 & 10 & 15 & 1 & 116 \\
\hline Total & 98 & 10 & 20 & 2 & 130 \\
\hline
\end{tabular}

Table 3. Colour frequencies of paintings documented at Ngiangu.

\begin{tabular}{|l|r|r|}
\hline \multicolumn{1}{|c|}{ Determinate Picture Colour(s) } & Frequency & \% of Total \\
\hline Red & 124 & 95.3 \\
\hline Red/White & 1 & 0.8 \\
\hline Mulberry & 3 & 2.3 \\
\hline Black & 1 & 0.8 \\
\hline Blue & 1 & 0.8 \\
\hline Total & $\mathbf{1 3 0}$ & $\mathbf{1 0 0}$ \\
\hline
\end{tabular}

\section{Regional Comparisons}

Figurative vs. Non-Figurative Imagery

Brady (2005) has observed a clear spatial pattern across Torres Strait in the proportion of figurative and nonfigurative motifs. Figurative motifs appear in abundance in the north (Dauan) and steadily decrease southwards. Conversely, non-figurative motifs appear in abundance in the south and steadily decrease northwards, indicating a clear shift towards non-figurative imagery in the southern half of the Strait. Ngiangu's high incidence of nonfigurative imagery clearly fits this regional trend.

\section{Totems and Non-Totemic Animal Species}

Formal comparisons between depictions of totemic and non-totemic animal species in rock art from across the Western and Central islands, and with other published and unpublished records of decorated material culture objects are useful in elucidating further patterning in rock art design forms in a regional context.

The totemic clan system in Western and Central Torres Strait (the Eastern islands were excluded from the totemic clan system thus creating a notable social boundary) was the central mechanism used to socially link Islanders based on a common totem (usually animals, or in rarer instances, an object or culture-hero). In Western and Central Torres Strait, totems were frequently depicted on material culture objects such as drums and wooden tobacco pipes, or scarred on people. Statements concerning the depiction of painted zoomorphs representing totems were first made by Haddon (1904:358) when he observed that the animals he documented from Kirriri (including a hammerhead shark, dugong and turtle) in 1888 were all totemic animals. Based on Haddon's observations, Jeremy Beckett - in the first scholarly article dedicated to Torres Strait rock art concluded that we regard 'all the animal figures [in Torres Strait rock art] as totemic species' (Beckett 1963:54). Additional statements regarding the meanings and role of animals in Torres Strait rock art (including Ngiangu) are plausible hypotheses based on local ethnography (e.g. Singe n.d.; cf. Barham 2000:279; McNiven and David 2004). As a result, depictions of animals in Ngiangu's rock art that conform to the animal species recorded by Haddon and Rivers (1904) for Kaurareg are considered to be totemic animals. However it should also be noted that while totemic animals frequently adorn material culture objects, the constant exchange of objects and the lack of information as to where the design was produced, creates difficulty in provenancing a particular object (apart from its collection locale) (Haddon and Rivers 1904).

Six of Ngiangu's 10 recorded zoomorphs (stingray, dugong, fish, fish/dugong [ $\mathrm{n}=2]$, quadruped), correspond with Haddon and Rivers' (1904) record of animal totems documented among Kaurareg in 1898. Comparisons involving two of the more distinctive totemic animals (dugong and stingray) from Ngiangu's rock art can be used to establish social relationships between islands based on the depiction of totemic animals. 


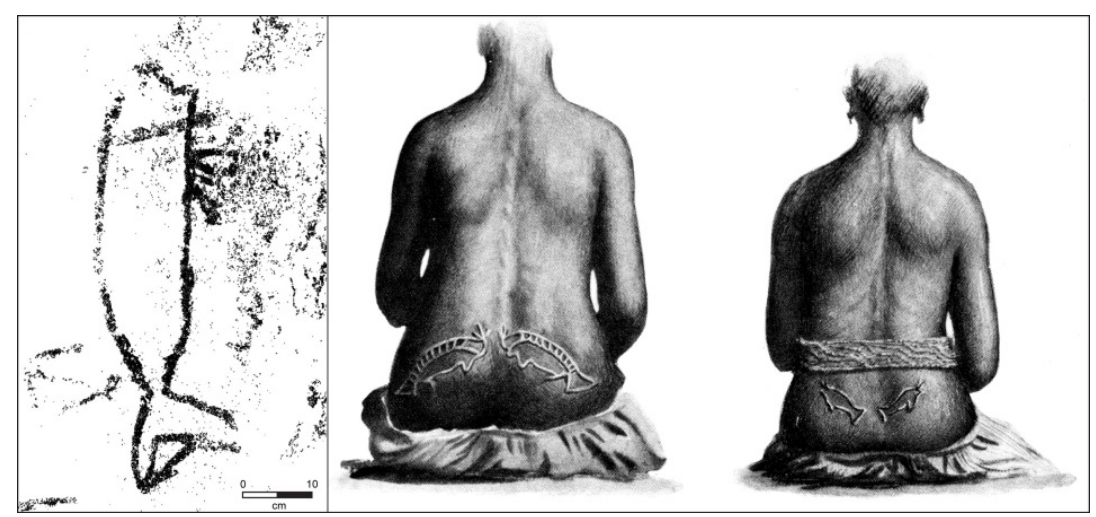

Figure 31. Left: black and white conversion of a dugong from Pouri Pouri Cave. Right: dugong totem scars on women from Mabuyag and Badu (from Haddon 1904:Plate 9).

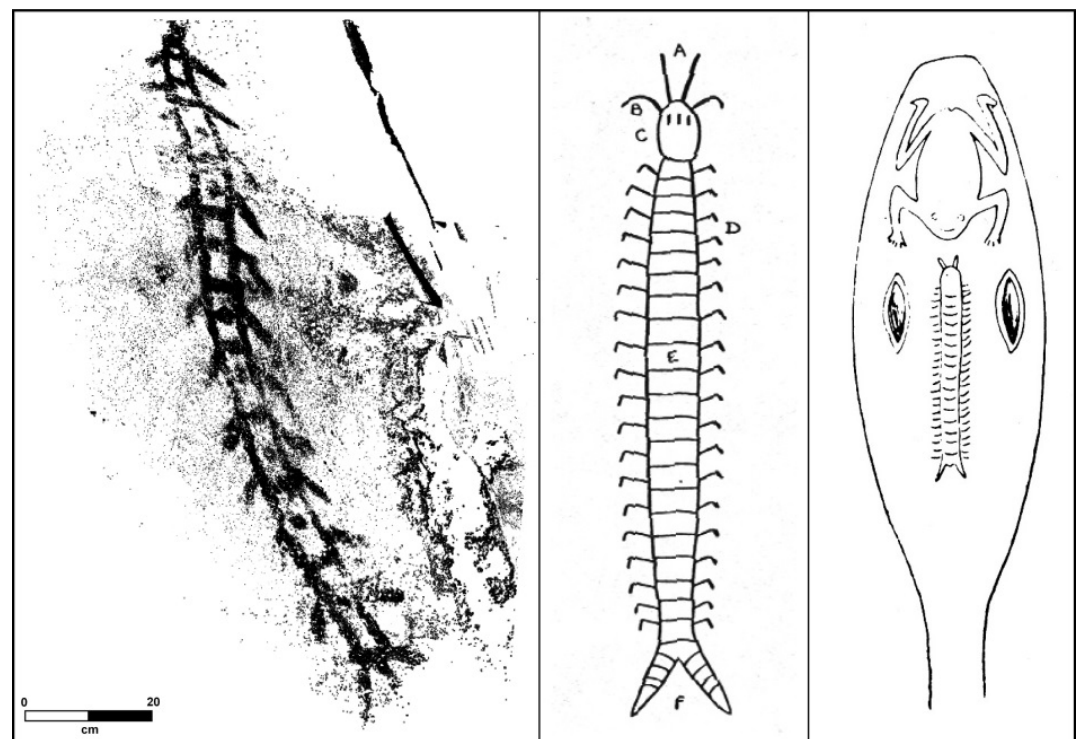

Figure 32. Left: black and white conversion of a centipede from Fern Cave. Middle: centipede design cut on a woman in the Eastern islands (Myers and Haddon 1908:156). Right: engraved centipede on an omaiter (Haddon 1912:375).

One outlined dugong - depicted vertically with its crescent-shaped tail pointing downwards - was documented from Pouri Pouri Cave (Figure 31). Brady (2005; Brady and Kaurareg Aboriginal Community 2007) has recorded other dugongs from Somerset (Cape York), Pulu and Kirriri. Dugong totemic representations extend across much of Western Torres Strait (e.g. carved on a dugong from Saibai, engraved on pearlshell from an unnamed island, and scarred on the back of two women one from Mabuyag, one from Badu; Haddon and Rivers 1904 163, 169; Haddon 1904:Plate 9) indicating a social relationship based on the visual association of dugong totemic representations between island communities across Western Torres Strait (cf. Brady 2008).

One stingray painting from Ngiangu consists of an outlined body with a triangular tail. The only other stingray rock painting has been documented at Muralag (Brady and Kaurareg Aboriginal Community 2007) and also features an outlined body with a three-pronged tail, the middle line being the longest. Material culture correlates have been recorded across much of the Torres Strait region. For example, a pipe collected from Parama off the southwestern Papua New Guinea coast (Haddon 1946), and a comb handle collected from Yam [Iama] in the Central islands (Haddon and Rivers 1904:169) contains stingray engravings. Additionally, Haddon (1904:Plate 11, Figures 6-7) documented a stingray sculpture from Tudu (Central islands) which Moore $(1989: 32,35)$ notes was probably a totemic pendant worn around the owner's neck.

Non-totemic animal species documented at Ngiangu consist of three centipedes $(n=3)$ and a crayfish $(n=1)$. Two forms of centipedes have been recorded here: a straight or slightly wavy line drawn with short lines attached at a perpendicular angle from Pouri Pouri Cave; and a series of interlinked rectangles - each with a dot in the middle - and short $\bigwedge$-shapes extending from both sides of the body from Fern Cave. While only one similar centipede rock painting (of the wavy line variety) has been reported from elsewhere in Torres Strait (Badu, see Brady 2005), both design forms occur on decorated material objects and as a scarred design on people. The second, rectangular form of centipede has been recorded by Haddon on the head of an omaiter or maid wap (a long spear similar to a dugong harpoon) - an implement used in sorcery on the Eastern islands (Haddon 1908:223-224) (Figure 32). One of Haddon's informants from the Eastern islands explained that centipedes were often used in sorcery; their bites were sometimes used as a threat to the unfortunate subjects of sorcery (Haddon 1908:223). Accordingly, Haddon (1912:353) remarked that 'the representation of the poisonous centipede would be very appropriate' on an omaiter or maid wap. 
Both forms of the Ngiangu centipede have been documented as a scar design on women (on the calf, breast or upper arm) from southwestern Papua New Guinea (Mobobo village in the Trans-Fly, Western Province) and in the Eastern islands of Torres Strait, as a token of mourning for relatives or parents (Myers and Haddon 1908:154-156). Consequently, the centipede, as a design form, has an ethnographic association with death, mourning and sorcery activities. The design's distribution spans the Western and Eastern islands, into Mobobo, Papua New Guinea and to West Papua on three different media.

One heavily deteriorated red crayfish painting was recorded from Fern Cave. This painting is drawn with an outlined body and internal decoration consisting of diagonal and horizontal lines. In 2000, McNiven et al. (2004b) recorded a crayfish from the Kabadul Kula rock art site on Dauan which is also outlined and features a

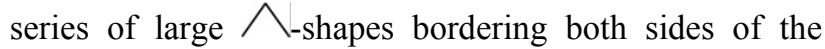
body - a design feature not observed at Ngiangu. As a result, differences in the depiction of the crayfish motif are apparent between the Top Western and South-Western islands. Additionally, Haddon's (1904:4) report of a crayfish rock painting at Pulu in 1898 enlarges the distribution of this specific motif form. No material culture correlates can be established for crayfish thus far.

\section{Colours}

The wide range of colours and techniques utilised at Ngiangu reveals a clear difference with other documented rock art sites in the northern half of Torres Strait. While red paintings dominate throughout the Torres Strait region, rock art sites from the Kaurareg Archipelago (including Ngiangu) and at Somerset feature notable similarities in the range of colours used (Brady 2005). Brady has noted that mulberry and black paintings are found exclusively at Somerset and Ngiangu in the SouthWestern islands. Additionally, paintings incorporating white (monochrome and bichrome) account for a total of 54 pictures from the Torres Strait region; 53 are located in the geographically circumscribed South-Western islands and Somerset. Brady suggests that colour distributions involving pigments other than red parallel the location of allied groups documented during the nineteenth century (e.g. Muralag, Ngiangu and Somerset).

\section{Re-Assessment of Individual Motifs \\ Anthropomorph}

A preliminary interpretation offered by Coleman (nda:67) of one of the two anthropomorphs recorded on the island, suggests a similarity in design convention between this picture and designs found on gope boards from southwestern Papua New Guinea. The painted anthropomorph in question consists of a concentric heartshaped head with one infilled circle (eye) (the other half of the face has suffered water damage). The lower half of the image is also damaged although an outlined rectangle drawn with two near-horizontal lines in the middle and bisected by a vertical line can be discerned. Approximately $5 \mathrm{~cm}$ left of the anthropomorph is an inverted triangle variant with a vertical line extending from the horizontal line of the triangle. Coleman had previously interpreted these two pictures anthropomorph and triangle variant - as one composite

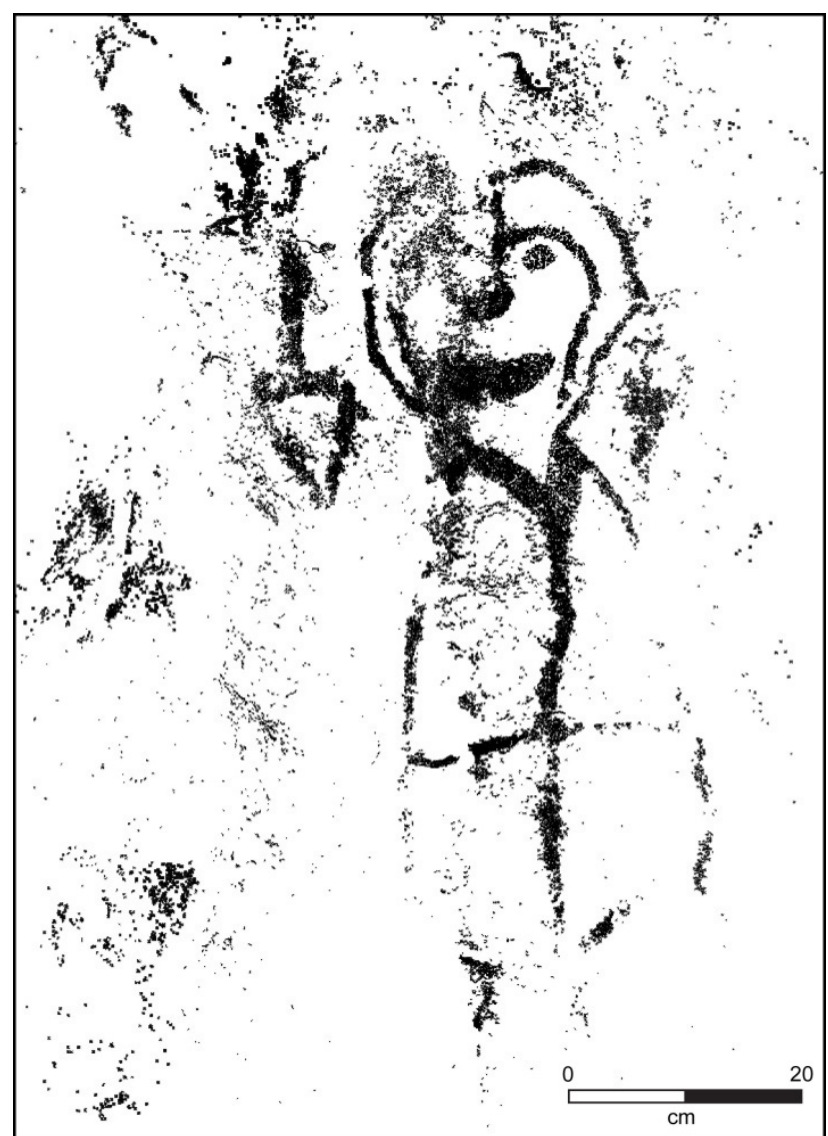

Figure 33. Mystery Man Cave: black and white conversion of an anthropomorph and triangle variant.

image whereby the triangle variant is a 'tassle-like appendage curving from the top of the head' (Coleman nd-a:67). However, computer enhancement of these two pictures failed to reveal any evidence linking the anthropomorph with the triangle variant (Figure 33). The primary structural features of gope boards consist of an oblong face with a central line. Eyes (concentric circle or single circle) are positioned on both sides of the central line while noses are usually bisected by the central line. Mouths - sometimes with embellishments such as vertical lines drawn through the middle - are usually positioned at the base of the central line. Other features on the boards consist of carved animals, perimeter decorations and attachments such as tassles and feathers (see Welsch et al. 2006). Given that the facial features of the Ngiangu anthropomorph do not conform to the primary characteristics of faces on gope boards, Coleman's original assessment of a New Guinea origin/influence must be reconsidered. Indeed, this painting does not appear to have any formal similarities with any of the other published anthropomorphs from Torres Strait rock art.

\section{Canoes}

Coleman's observation of several canoes in Ngiangu's rock art also merits consideration in the context of regional interaction. Coleman (nd-a:70) recorded a total of three canoes which he considered 'watercraft of nonTorres Strait origin' - all of Indonesian origin. Coleman identified a 'Macassan prau', a canoe with a lateen sail, and a third unidentified canoe. He provided an image of the supposed Macassan prau, although the existence of the other two canoes of a non-Torres Strait origin could 


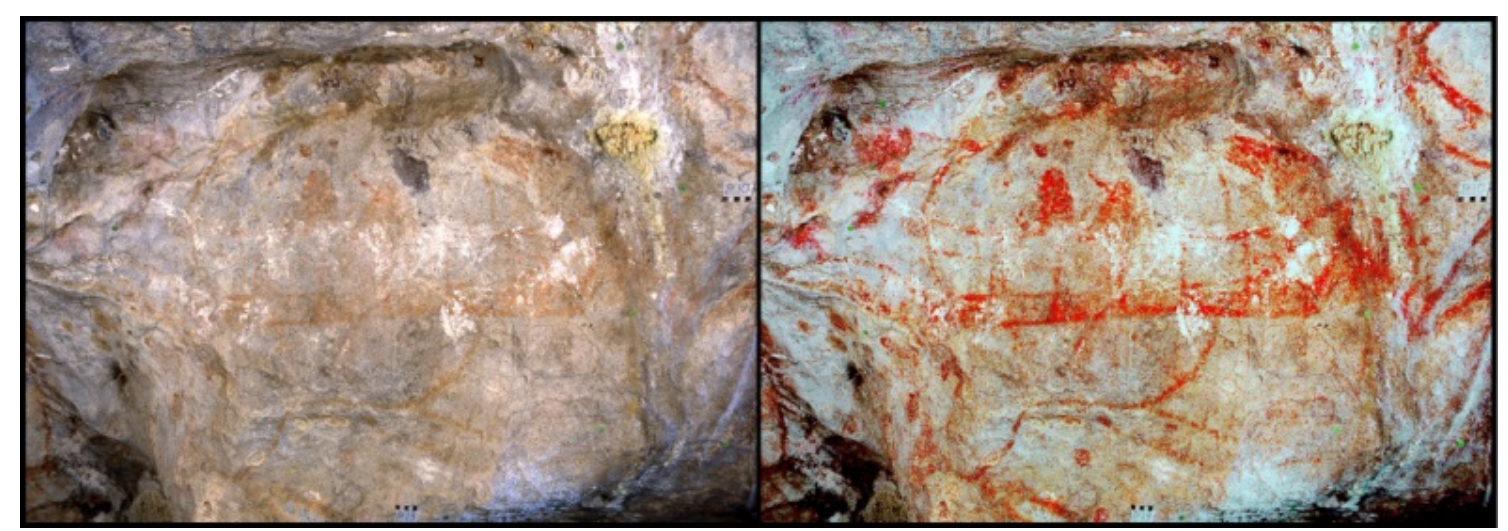

Figure 34. Computer enhancement of Coleman's 'prau’; Brady (2005) has since reclassified the image as a series of individual geometric shapes.

not be verified. Based on the form of Colemans's sketch, the photograph, subsequent computer enhancement of the 'Macassan prau' and comparison with other painted praus recorded in the rock art from areas known to have contact with Macassan trepangers (e.g. Clarke and Frederick 2006), there is considerable doubt as to whether this painting is similar in form to a Southeast Asian sailing vessel (Figure 34). Instead, this image has been classified by Brady (2005) as a series of individual geometric shapes (circle and triangle variants). Additionally, Coleman's prau is not similar to any known rock paintings of boats from Indonesia or other parts of Southeast Asia, or for that matter Torres Strait. Coleman (nd-a:74) also identified 'a group of essentially similar canoes ... distinctive for their symmetrically up-turned bow and stern and that they are shown segmented by either vertical bars or narrow ' $X$ 's'. These 'canoes' could not be identified in this recent inventory of Ngiangu's rock art and thus remain unaccounted for. Recent rock art research in island Southeast Asia (Timor, West Papua and Kei Kecil in the southeast Moluccas) has revealed some similar design conventions between these three regions (e.g. scrolls, schematic designs, and curvilinear designs) (O’Connor 2003). However, formal similarities between Ngiangu's rock art and documented rock paintings from island Southeast Asia which exhibit the characteristics noted above have failed to yield any artistic correlations between the two regions. This lack of artistic similarity suggests a discontinuity in artistic systems between the two regions and reinforces Brady's (2005) recent observation of discontinuities between Torres Strait region rock art and island Southeast Asia and West Papua.

\section{The Indigenous Archaeology of Ngiangu: Symbols of} Interaction?

Based on rock art evidence, Brady and Kaurareg Aboriginal Community (2007) have recently argued that the Kaurareg Archipelago represents a distinct transition zone positioned between Cape York Aboriginal groups to the south, and Melanesian-influenced Torres Strait Islanders to the north. Kaurareg's geographical position places them in a unique situation where they were exposed to both Islander and Aboriginal cultural influences. We argue here that Ngiangu's material evidence, especially the rock art, further highlights the transitional nature of Kaurareg culture.
Rock art offers the most clues to understanding the broader significance of Ngiangu in the context of interregional interaction. At a Torres Strait level, links between distinctive images documented in Ngiangu's rock art, depicted on portable objects, and scarred as designs on people, indicate that designs crossed between fixed and portable media and across well-defined social (e.g. totemic clan system) and linguistic boundaries (Western and Central islands spoke similar languages; Eastern Islanders spoke a Papuan language; see Brady 2008). It should be pointed out that the art described here is believed to be of a relatively similar age. In the context of rock art, relative dating techniques have revealed a maximum age of 1200-1400 years ago although much more recent dates of only a few hundred years have been identified and/or suggested for most other paintings (e.g. Brady 2005; David et al. 2004b, 2004c; McNiven et al. 2004b; McNiven et al. 2009a; Sharp 1992). In addition, wooden material culture objects in a tropical climate would most likely have a somewhat short lifespan meaning images on wood and images on rock walls are of a similar age. Furthermore, scarred designs recorded by Haddon provide a date for when some of these designs were still being produced.

The symbolic nature of distinctive motifs (e.g. the centipede, see above) lies in their ability to give meaning to the social seascape. These images are representative of a material expression that has been acquired and produced by social processes involving direct and/or indirect social interaction with other groups across the region (Brady 2008). As a result, these designs may be viewed as symbols referencing direct or indirect social interaction (David 2002). However, links with Cape York are not expressed in terms of distinctive motifs, but instead through similarly high proportions of non-figurative (abstract) imagery (when compared with the rest of Torres Strait) and a greater variation in colours used in the production of images. These links suggest that visual expressions in the Kaurareg Archipelago reflect the Kaurareg's position between two different cultural realms. While further research is currently being undertaken to explore the notion of more links between the Kaurareg Archipelago and Cape York the Ngiangu evidence certainly contributes towards this aim. 


\section{Conclusion}

The Queensland Museum's Expeditions to Ngiangu in 1985 and 1990 have played an important role in understanding the archaeology of the western-most island in Torres Strait in the context of Kaurareg identity and inter-regional interaction. From an Indigenous perspective, the well-known oral tradition of Pötikain and Ngiangu, the material culture record, and the rich visual imagery found in the numerous caves reveals how Ngiangu formed an important part of the Kaurareg seascape. Like many other small-size islands in Torres Strait, Ngiangu does not appear to have been permanently inhabited but instead was used/visited periodically for a variety of purposes including the production of stone arrangements and artistic activity. Analysis of this artistic activity has been particularly useful at highlighting social links with islands throughout the Torres Strait seascape and reassessing previous speculation about Southeast Asian influences. These and other cultural markers from the island including pottery and adzes clearly reveal its significance on both local and broader regional scales.

\section{Acknowledgements}

The authors wish to acknowledge the research and field investigation relating to Ngiangu's rock art and European historical writing conducted by the late Ron Coleman during the period of his employment as Curator of Maritime Archaeology at the Queensland Museum. His preliminary reports, field notes and sketches together with the photographic coverage of the images on the cave walls taken by Queensland Museum photographer, Gary Cranitch, provided the foundation on which this paper was compiled. LMB extends his thanks to the Kaurareg Aboriginal community for their patience, support and friendship during the writing of this paper. Special thanks go to the Kaurareg Elders Corporation and the Kaurareg Land and Sea Management Corporation for their encouragement and guidance relating to Kaurareg cultural heritage. LMB also thanks Michael Quinnell for assistance at the Queensland Museum, Wendy van Duivenvoorde (Western Australian Museum) for help in tracking down references, and members of the Queensland Museum Expedition to Ngiangu for their invitation to assist in the preparation of this paper. Peter Marquis-Kyle provided information on the history of the lighthouse. Writing of this paper was funded in part by an ARC Discovery Grant (DP0984998) to LMB. Thanks also to Shelley Greer and an anonymous referee for comments and suggestions.

\section{References}

Ashmore, S. 1844 Booby Island (To the Editors of the Sydney Morning Herald). Sydney Morning Herald 11 March:2.

Bach, J. (ed.) 1986 The Bligh Notebook: 'Rough Account Lieutenant W. Bligh's Voyage in the Bounty's Launch from the Ship to Tofua \& from thence to Timor', 28 April to 14 June 1789, with a Draft List of the Bounty Mutineers. Canberra: National Library of Australia.

Barham, A.J. 2000 Late Holocene maritime societies in the Torres Strait Islands, northern Australia - Cultural arrival or cultural emergence? In S. O'Connor and P. Veth (eds), East of Wallace's Line: Studies of Past and Present Maritime Cultures of the Indo-Pacific Region, pp.223-314. Modern Quaternary Research in Southeast Asia 16. Rotterdam: Balkema.

Beaglehole, J.C. 1955 The Journals of Captain Cook on his Voyages of Discovery. Cambridge: Hakluyt Society.

Beckett, J. 1963 Rock art in the Torres Strait Islands. Mankind 6(2):52-54.
Brady, L.M. 2005 Painting Patterns: Torres Strait Region RockArt, NE Australia. Unpublished $\mathrm{PhD}$ thesis, Monash University, Clayton.

Brady, L. M. 2006 Documenting and analyzing rock paintings from Torres Strait, NE Australia, with digital photography and computer image enhancement. Journal of Field Archaeology 31(4):363-379.

Brady, L.M. 2008 Symbolic language in Torres Strait, NE Australia: Images from rock art, portable objects and human scars. Antiquity 82:336-350.

Brady, L.M. and Kaurareg Aboriginal Community 2007 A middle ground? Recent archaeological investigations from the Kaurareg Archipelago, south-western Torres Strait, Queensland. Australian Archaeology 65:17-29.

Carter, M. 2004 North of the Cape and South of the Fly: The Archaeology of Settlement and Subsistence on the Murray Islands, Eastern Torres Strait. Unpublished $\mathrm{PhD}$ thesis, James Cook University, Townsville.

Clarke, A. and U. Frederick 2006 Closing the distance: Interpreting cross-cultural engagements through Indigenous rock-art. In I. Lilley (ed.), Archaeology of Oceania: Australia and the Pacific Islands, pp.116-133. Oxford: Blackwell Publishing.

Cole, N. and A. Watchman 1993 Blue paints in prehistory: Preliminary investigations into the use of the colour blue in Aboriginal paintings at Laura, Cape York. Rock Art Research 10(1):58-61.

Coleman, R. 1991 A Preliminary Report to the Heritage Branch Department of Environment and Conservation on Investigations at Booby Island. Unpublished report to Maritime History and Archaeology Department, Queensland Museum, Brisbane.

Coleman, R. nd-a Booby Island: A Survey of the Pre-Historical, Historical and Cultural Significance. Unpublished report to Board of Trustees, Queensland Museum, Brisbane.

Coleman, R. nd-b Report on Brief Survey of Booby Island, Torres Strait (Undertaken in November, 1985). Unpublished report to Maritime History and Archaeology Department, Queensland Museum, Brisbane.

Cox, G. and A. Watchman 2000 Coarse Earthenware Pot Fragment, Pot Hole, Booby Island. Unpublished report to Queensland Museum, Brisbane.

Crouch, J., I.J. McNiven, B. David, C. Rowe and M. Weisler 2007 Berberass: Marine resource specialisation and environmental change in Torres Strait during the past 4000 years. Archaeology in Oceania 42(2):49-64.

David, B. 2002 Landscapes, Rock-Art and the Dreaming: An Archaeology of Preunderstanding. London: Leicester University Press.

David, B., J. Brayer, I.J. McNiven and A. Watchman 2001 Why digital enhancement of rock paintings works: Rescaling and saturating colours. Antiquity 75:781-792.

David, B., J. Crouch and U. Zoppi 2005 Historicizing the spiritual: $B u$ shell arrangements on the island of Badu, Torres Strait. Cambridge Archaeological Journal 15(1):7191.

David, B. and I.J. McNiven 2004 Western Torres Strait Cultural History Project: Research design and initial results. In I.J. McNiven and M. Quinnell (eds), Torres Strait Archaeology and Material Culture, pp.199-208. Memoirs of the Queensland Museum, Cultural Heritage Series 3. Brisbane: Queensland Museum. 
David, B., I.J. McNiven, W. Bowie, M. Nomoa, P. Ahmat, J. Crouch, L. Brady, M. Quinnell and L. Brady 2004c Archaeology of Torres Strait turtle-shell masks: The Badu Island cache. Australian Aboriginal Studies 1:18-25.

David, B., I.J. McNiven, J. Crouch, Mura Badulgal Corporation Committee, R. Skelly, B. Barker, K. Courtney and G. Hewitt 2009 Koey Ngurtai: The emergence of a ritual domain in western Torres Strait. Archaeology in Oceania 44(1):1-17.

David, B., I.J. McNiven, L. Manas, J. Manas, S. Savage, G. Neliman and L. Brady 2004b Goba of Mua: Archaeology working with oral tradition. Antiquity 78:158-172.

David, B. and Mura Badulgal 2006 What happened in Torres Strait 400 years ago? Ritual transformations in an island seascape. Journal of Island and Coastal Archaeology 1:123143.

David, B., Mura Badulgal (Torres Strait Islanders) Corporation, I. McNiven, J. Crouch and L. Brady 2004a The Argan stone arrangement complex, Badu Island: Initial results from Torres Strait. Australian Archaeology 58:1-7.

Delaney, W. 1990 Booby Island, The European presence. Bulletin of the Australian Institute of Maritime Archaeology 14(2):49-54.

Greer S., S. McIntyre-Tamwoy and R. Henry 2011 Sentinel sites in a cosmo-political seascape. In ISIC 7 - 2011 7th International Small Islands Conference, 12-15 June 2011, Airlie Beach, QLD, Australia. Retrieved 21 May 2013 from http://sicri-network.org.

Haddon, A.C. 1890 The ethnography of the western tribe of Torres Straits. Journal of the Anthropological Institute 19:297-440.

Haddon, A.C. (ed.) 1904 Reports of the Cambridge Anthropological Expedition to Torres Straits: Sociology, Magic and Religion of the Western Islanders. Vol. 5. Cambridge: Cambridge University Press.

Haddon, A.C. (ed.) 1908 Reports of the Cambridge Anthropological Expedition to Torres Strait: Sociology, Magic and Religion of the Eastern Islanders. Vol. 6. Cambridge: Cambridge University Press.

Haddon, A.C. (ed.) 1912 Reports of the Cambridge Anthropological Expedition to Torres Straits: Arts and Crafts. Vol. 4. Cambridge: Cambridge University Press.

Haddon, A.C. 1946 Smoking and tobacco pipes in New Guinea. Philosophical Transactions of the Royal Society of London, Series B, Biological Sciences 232(586):1-278.

Haddon, A.C. and W.H.R. Rivers 1904 Totemism. In A.C Haddon (ed.), Reports of the Cambridge Anthropological Expedition to Torres Straits: Sociology, Magic and Religion of the Western Islanders, pp.153-193. Vol. 5. Cambridge: Cambridge University Press.

Heeres, J.E. 1899 The Part Borne by the Dutch in the Discovery of Australia 1606-1765. London: Luzac \& Co.

Hiscock, P. 1988 A cache of tulas from the Boulia District, western Queensland. Archaeology in Oceania 23(2):60-70.

Hitchcock, G. 2004 Torres Strait origin of some stone-headed clubs from the Torassi or Bensbach River area, southwest Papua New Guinea. In I.J. McNiven and M. Quinnell (eds), Torres Strait Archaeology and Material Culture, pp.305316. Memoirs of the Queensland Museum, Cultural Heritage Series 3. Brisbane: Queensland Museum.

King, P.P. 1827 Narrative of a Survey of the Intertropical and Western Coasts of Australia. London: John Murray.
Lawrence, D. 1994 Customary exchange across Torres Strait. Memoirs of the Queensland Museum 34(2):241-446.

Lawrie, M. 1970 Myths and Legends of Torres Strait. St Lucia: University of Queensland Press.

MacGillivray, J. 1852 Narrative of the Voyage of H.M.S. Rattlesnake, Commanded by the Late Captain Owen Stanley, R.N., F.R.S. during the years 1846-1850. Including Discoveries and Surveys in New Guinea, the Louisiade Archipelago, etc. Vol. I. London: T. \& W. Boone.

McIntyre-Tamwoy, S. and R. Harrison 2004 Monuments to colonialism? Stone arrangements, tourist cairns, and turtle magic at Evans Bay, Cape York. Australian Archaeology $59: 31-42$.

McNiven, I.J. 1998 Enmity and amity: Reconsidering stoneheaded club (gabagaba) procurement and trade in Torres Strait. Oceania 69(2):94-115.

McNiven, I.J. 2003 Saltwater people: Spiritscapes, maritime rituals and the archaeology of Australian Indigenous seascapes. World Archaeology 35(3):329-349.

McNiven, I.J. 2006 Dauan 4 and the emergence of ethnographically-known social arrangements across Torres Strait during the last 600-800 years. Australian Archaeology $62: 1-12$.

McNiven, I.J. and A. Bedingfield 2008 Past and present marine mammal hunting rates and abundances: Dugong (Dugong dugon) evidence from Dabangai bone mound, Torres Strait. Journal of Archaeological Science 35(2):505-515.

McNiven, I.J., L.M. Brady and A.J. Barham 2009a Kabadul Kula and the antiquity of Torres Strait rock art. Australian Archaeology 69:29-40.

McNiven, I.J. and B. David 2004 Torres Strait rock-art and ochre sources: An overview. In I.J. McNiven and M. Quinnell (eds), Torres Strait Archaeology and Material Culture, pp.199-208. Memoirs of the Queensland Museum, Cultural Heritage Series 3. Brisbane: Queensland Museum.

McNiven, I.J., B. David, L. Brady and J. Brayer 2004b Kabadul Kula rock-art site, Dauan Island, Torres Strait. In I.J. McNiven and M. Quinnell (eds), Torres Strait Archaeology and Material Culture, pp.227-256. Memoirs of the Queensland Museum, Cultural Heritage Series 3. Brisbane: Queensland Museum.

McNiven, I.J., B. David, Goemulgau Kod and J. Fitzpatrick 2009b The Great Kod of Pulu: Mutual historical emergence of ceremonial sites and social groups in Torres Strait, northeast Australia. Cambridge Archaeological Journal 19(3):291-317.

McNiven, I.J., W.R. Dickinson, B. David, M. Wiesler, F. Von Gnielinski, M. Carter and U. Zoppi 2006 Mask Cave: Redslipped pottery and the Australian-Papuan settlement of Zenadh Kes (Torres Strait). Archaeology in Oceania 41(2):49-81.

McNiven, I.J. and R. Feldman 2003 Ritual orchestration of seascapes: Hunting magic and dugong bone mounds in Torres Strait, NE Australia. Cambridge Archaeological Journal 13(2):169-194.

McNiven, I.J. and F.E. Von Gnielinski 2004 Stone club head manufacture on Dauan Island, Torres Strait. In I.J. McNiven and M. Quinnell (eds), Torres Strait Archaeology and Material Culture, pp.291-304. Memoirs of the Queensland Museum, Cultural Heritage Series 3. Brisbane: Queensland Museum. 
McNiven, I.J. and F.E. Von Gnielinski 2008 A decorated stone club head (gabagab) from Mua, Torres Strait. In B. David, L. Manus and M. Quinnell (eds), Gelam's Homeland: Cultural and Natural History on the Island of Mua, Torres Strait, pp.553-558. Memoirs of the Queensland Museum, Cultural Heritage Series 4(2). Brisbane: Queensland Museum.

McNiven, I.J., F.E. Von Gnielinski and M. Quinnell 2004a Torres Strait and the origin of large stone axes from Kiwai Island, Fly River estuary (Papua New Guinea). In I.J. McNiven and M. Quinnell (eds), Torres Strait Archaeology and Material Culture, pp.271-290. Memoirs of the Queensland Museum, Cultural Heritage Series 3. Brisbane: Queensland Museum.

Moore, D.R. 1972 Cave paintings from northern Cape York Peninsula. Mankind 8(3):207-208.

Moore, D.R. 1973 Preliminary Report on an Archaeological Survey of Cape York and the Prince of Wales Group of Islands. Unpublished report on file at Heritage Branch, Environmental Protection Agency, Brisbane.

Moore, D.R. 1979 Islanders and Aborigines at Cape York: An Ethnographic Reconstruction Based on the 1848-1850 'Rattlesnake' Journals of O.W. Brierly and Information he Obtained from Barbara Thompson. Canberra: Australian Institute of Aboriginal Studies.

Moore, D.R. 1986 Results of an Archaeological Survey of Cape York \& Prince of Wales Island. Unpublished report on file at Heritage Branch, Environmental Protection Agency, Brisbane.

Moore, D. R. 1989 Arts and Crafts of Torres Strait. Aylesbury: Shire.

Myers, C.S. and A.C. Haddon 1908 Funeral ceremonies. In A.C. Haddon (ed.), Cambridge Anthropological Expedition to Torres Straits: Sociology, Magic and Religion of the Eastern Islanders, pp.126-162. Vol. 6. Cambridge: Cambridge University Press.

Nicholson, I. 1996 Via Torres Strait: A Maritime History of the Torres Strait Route and the Ships' Post Office at Booby Island. Yaroomba: Roebuck.

O'Connor, S. 2003 Nine new painted rock art sites from East Timor in the context of the western Pacific Region. Asian Perspectives 42(1):96-128.
Prideaux, P. 1988 From Spear to Pearl Shell. Brisbane: Booralong Publications.

Rhodes, F. 1934 Pageant of the Pacific. Sydney: F.J. Thwaites Pty Ltd.

Sharp, N. 1992 Footprints along the Cape York Sandbeaches. Canberra: Aboriginal Studies Press.

Sharp, N. 2002 Saltwater People: The Waves of Memory. Crow's Nest: Allen and Unwin.

Singe, J. 1979 The Torres Strait: People and History. St Lucia: University of Queensland Press.

Singe, J. nd Aspects of Rock Painting in the Torres Strait with an Emphasis on Muralug Island Group (to which is attached copies of drawings of rock paintings from various sites). Unpublished manuscript, Thursday Island High School.

Stewart, F. 1845 Loss of the 'Hydrabad' and 'Coringa Packett'. Sydney Morning Herald 14 August:2.

Stokes, J.L. 1846 Discoveries in Australia; With an Account of the Coasts and Rivers Explored and Surveyed During the Voyage of the H.M.S. Beagle, in the Years 1837-38-39-4041-42-43. 2 vols. London: T \& W Boone.

Vanderwal, R.L. 2004 Early historical sources for the top western islands in the western Torres Strait exchange network. In I.J. McNiven and M. Quinnell (eds), Torres Strait Archaeology and Material Culture, pp.257-270. Memoirs of the Queensland Museum, Cultural Heritage Series 3. Brisbane: Queensland Museum.

Von Gnielinski, F.E., T.J. Denaro, P. Wellman and C.F. Pain 1998 Torres Strait region. In J.H.C. Bain and J.J. Draper (eds), North Queensland Geology, pp.159-164. Brisbane: AGSO Bulletin 240/Queensland Geology 9.

Welsch, R.L., V-L Webb and S. Haraha 2006 Coaxing the Spirits to Dance: Art and Society in the Papuan Gulf of New Guinea. Hanover: Hood Museum of Art, Dartmouth College.

Wright, D. and W. Dickinson 2009 Movement of ideas not materials: Locally manufactured pottery on Mabuyag Island, western Torres Strait. Archaeology in Oceania 44(1):38-41. 